
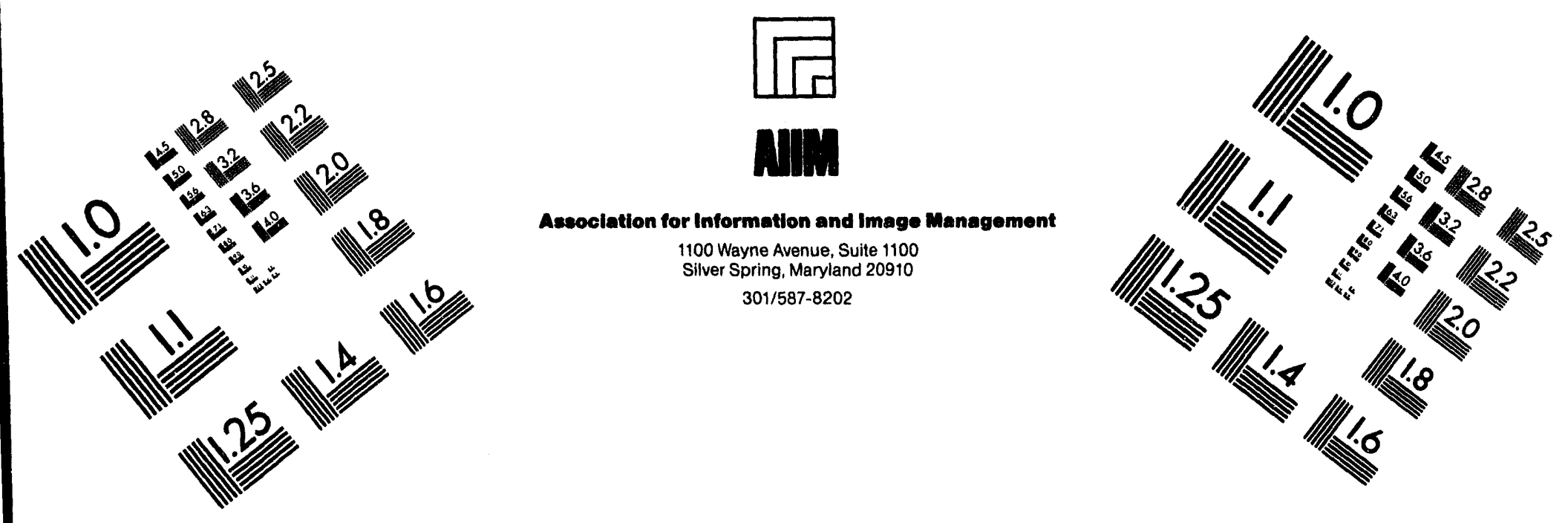

\title{
Centimeter
}

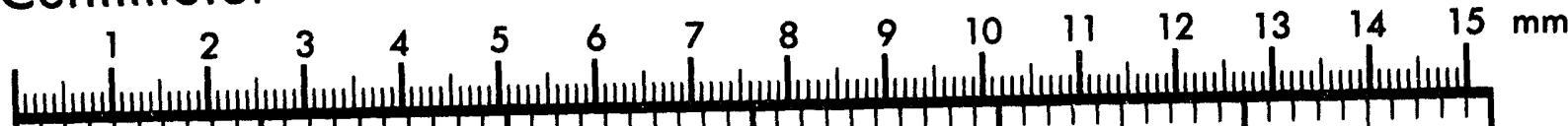

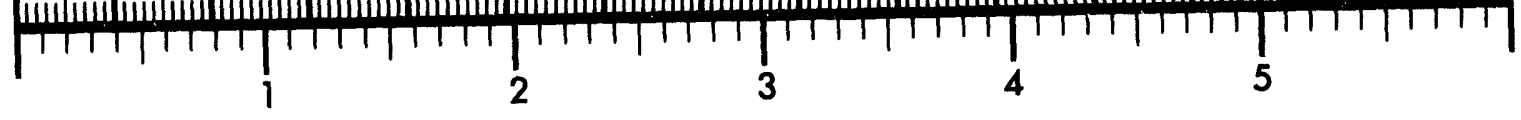
Inches
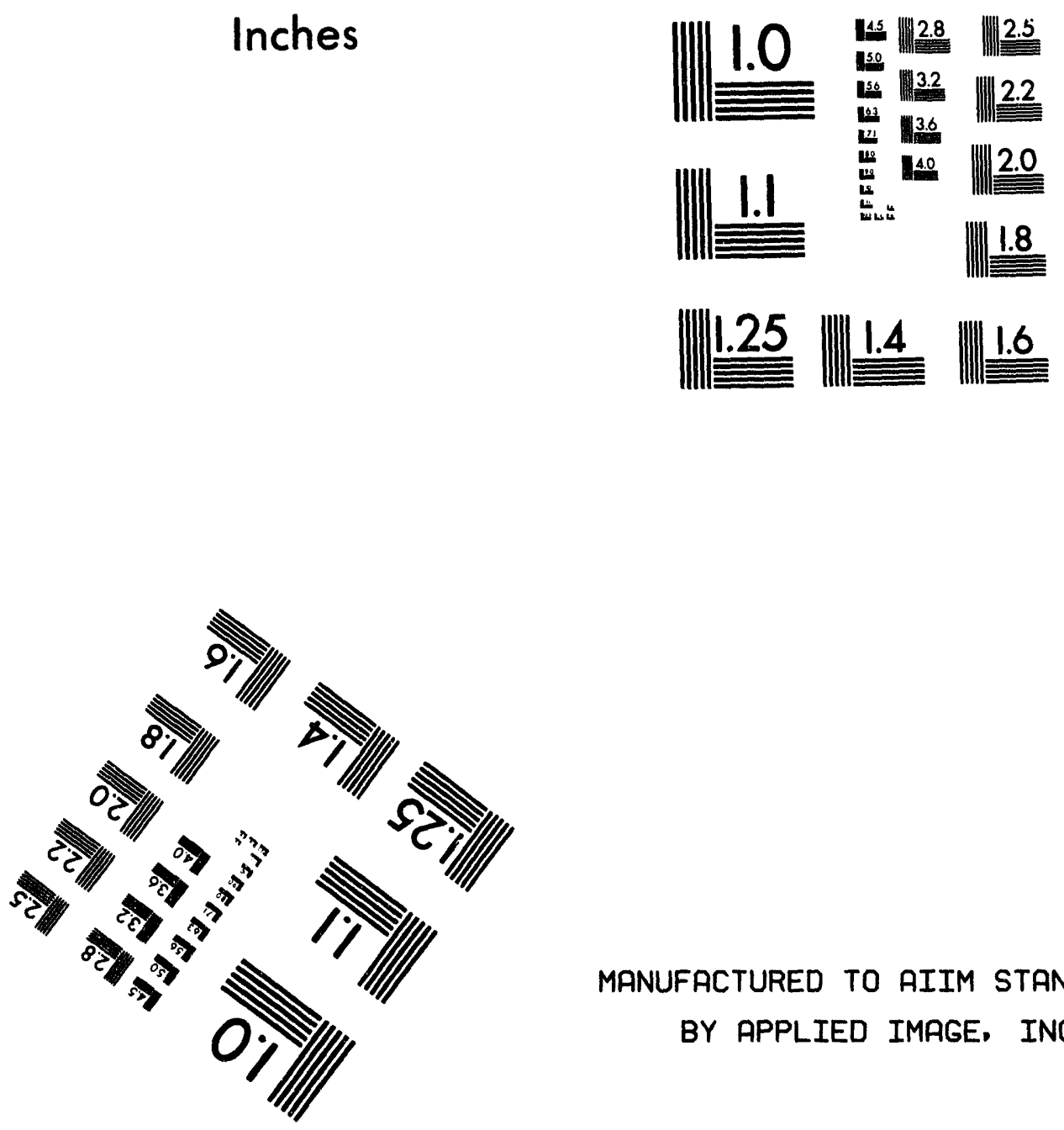

MANUFACTURED TO AIIM STANDARDS BY APPLIED IMAGE, INC.

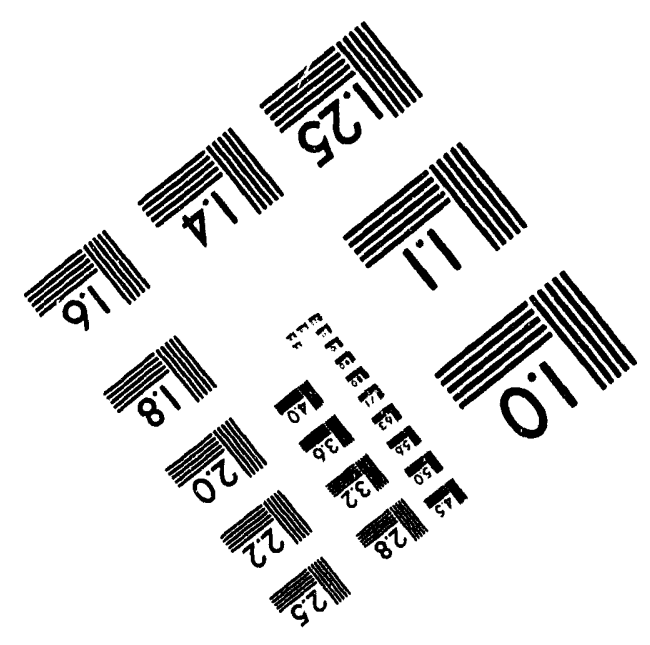





\section{Research Program on Fractured Petroleum Reservoirs \\ DE-FG22-93BC14875}

RESERVOIR ENGINEERING RESEARCH INSTITUTE

January 31, 1993

Contract Date: September 30, 1993

DoE Program Manager: Rhonda Patterson Lindsey

Principal Investigator: Abbas Firoozabadi

$4 Q .93$

October 1, through December 31, 1993

DISCLAIMER

This report was prepared as an account of work sponsored by an agency of the United States
Government. Neither the United States Government nor any age employees, makes any the United States Government nor any agency thereof, nor any of their bility for the accuracy, completeness, or or implied, or assumes any legal liability or responsiprocess disclosed, or represents that its usefulness of any information, apparatus, product, or ence herein to any specific commercial use would not infringe privately owned rights. Refermanufacturer, or otherwise does not necessarily cons, or service by trade name, trademark, mendation, or favoring by the United States Gonstitute or imply its endorsement, recomand opinions of authors expressed herein Government or any agency thereof. The views United States Government or any agency thereof not necessarily state or reflect those of the 


\section{RESERVOIR ENGINEERING RESEARCH INSTITUTE}

PROJECT 2 - SUPERSATURATION, CRITICAL SATURATION AND RESIDUAL GAS SATURATION IN POROUS MEDIA

SOLUTION GAS-DRIVE PROCESS IN HEAVY AND LIGHT OIL RESERVOIRS

4Q.93

October 1, through December 31, 1993

ABBAS FIROOZABADI

TORE MARKESET 


\section{SOLUTION GAS-DKIVE PROCESS IN HEAVY AND LIGHT OIL RESERVOIRS}

\section{SUMMARY}

A visual high-pressure core-holder has been designed and constructed to be used in critical gas saturation and some other measurements. The apparatus has been used to measure critical gas saturation for a low viscosity mixture. These measurements reconfirm our previously publiched data that critical gas saturation for low viscosity fluids are low-around 1 percent. The apparatus is being currently used to measure critical gas saturation of an 11 API oil. Unlike light oils, heavy oil reservoirs, especially fractured heavy oil reservoirs might have an extremely high recovery efficiency with solution gasdrive. The critical gas saturation is an important element of recovery efficiency for such reservoirs.

\section{INTRODUCTION}

A certain number of heavy oil reservoirs (with viscosities in the range of 200 to $5000 \mathrm{cp}$ at reservoir temperatures of 14 to $20^{\circ} \mathrm{C}$ ) are known to have a high recovery -around 15 to 20 percent by primary depletion. The high recovery is achieved in the absence of gravity drainage and water drive. Solution gas-drive is believed to be the only mechanism contributing to such high recoveries in heavy oil reservoirs. From common reservoir engineering knowledge, the primary recovery is estimated to be some 2 to 4 percent.

The Celtic field in Canada has produced oil under both primary recovery and cyclic steam conditions ${ }^{1}$. The saturated oil has viscosity of about $2000 \mathrm{cp}$ and the initial solution gas-oil ratio is $10 \mathrm{vol} / \mathrm{vol}$. The initial reservoir pressure was about 480 psia. Recovery factor to 1992 has been as high as 14 percent. Another peculiar behavior of the reservoir has been that oil rate would start low, then increase steadily to about ten times the initial rate and stabilize at high rates. Although thermal recovery has been 
experimented in this field, the unusually high primary production rates from solution gasdrive were considered key commercial exploitation. Ref. 2 mentions that in some of the heavy oil reservoirs in Canada, several wells which were prolific producers by primary production, showed very poor response to steam stimulation.

There are two key factors which affect the efficiency of a solution-gas drive process; 1) critical gas saturation, and 2) the mobility of gas phase. In addition to these factors, the mobility of the liquid phase may be also influenced indirectly. In light oil systems, our previous experimental work has revealed very low values of critical gas saturation ${ }^{3}$. Our measured critical gas saturations were in the range of 0.5 to 2 percent. These values are much lower than values reported by others in the literature. One purpose of this report is to reconfirm low values of critical gas saturation for low viscosity oils by using a visual core holder setup. Our theoretical work on gas evolution in porous media ${ }^{4}$ has led to the conclusion that the number of gas bubbles are small -- orders of magnitude less than the number of pores. This conclusion was reached by examining data on low viscosity and light fluids. In the theoretical model, the effect of liquid viscosity on gas bubble expansion was neglected and diffusion was assumed to be the major mechanism for bubble expansion. Such an assumption which is believed to be valid for low viscosity liquids may not be appropriate for heavy oil systems. In heavy oils, the number of gas bubbles formed initially may be very high if asphaltene materials in the crude could provide the nucleation active sites. As already mentioned, growth of gas bubbles may also be different from bubble growth in light oils. One main purpose of this project is to establish the evolution and growth of gas phase in heavy oil reservoirs. The issues of critical gas saturation, flow of isolated bubbles, and gas mobility have all to be addressed. Due to the nature of two-phase gas-oil flow in fractured porous media, recovery performance of a fractured heavy oil reservoir may benefit considerably from an efficient solution gas-drive process ${ }^{4}$. 
In this report, the experimental setup that has been constructed for the purpose of this project will be described first. The experimental results will then follow. Once sufficient experimental data are provided, a theoretical model will be attempted.

\section{EXPERIMENTAL}

A visual core holder was designed to provide visual observation of bubble formation, growth, and especially the nature of gas flow when the gas phase becomes mobile. In this design, the surface area of the core could be viewed at all times. In addition, a space of about $4 \mathrm{~cm}^{3}$ above the core outlet allows observation of nature of gas flow from the core.

Apparatus - The apparatus schematic is shown in Fig. 1. A Berea core, 2" in diameter and 8 "long is placed between two clear cast plastic endpieces. These two endpieces have the same diameter as the core and are 2 " long. The lower endpiece has 0.125 " diameter flow channel in the center. The upper endpiece has a cylindrical open space of $0.625 "$ diameter and depth of 0.8 ", leading to a cone and then a $0.125^{\prime \prime}$ diameter flow channel. The volume of the open space of the top endpiece is about $4 \mathrm{~cm}^{3}$. A teflon sleeve is heatshrunk around the core-endpiece assembly. The core-sleeve assembly is placed inside an adjustable length core holder. The core holder wall is also made of clear cast acrylic plastic. The space between the core holder wall and the teflon covered coreendpieces is filled with water to provide sleeve pressure.

Peripheral accessory equipment consists of a piston pump, multiloop controller, two pressure transducers for measuring inlet and outlet pressures of the core, resistive temperature detector (RTD), air conditioning unit, convection oven, video camera, video camera recorder (VCR), television screen (TV), and a personal computer (PC). The video camera is interfaced to the VCR which is interfaced to a TV. The RTD, air conditioning unit, convection oven, and pressure transducers are interfaced to the multiloop controller. The multiloop controller is interfaced to the PCs. A computer program in C language 
allows logging of pressures and temperature. The same program also simultaneously provides temperature control of the laboratory room $\left(77 \pm 0.3^{\circ} \mathrm{F}\right)$. The prevolume of the Berea is $93 \mathrm{~cm}^{3}$. The piston pump when the piston is at the top of the cylinder has a dead volume of $4 \mathrm{~cm}^{3}$. The total fluid prevolume at the start of the tests is measured to be 115 $\mathrm{cm}^{3}$; which includes the $4 \mathrm{~cm}^{3}$ volume of the upper endpiece open space, the deadend volume of the pump, the core PV, and the dead volume of the space between the endpieces and the core holder caps.

Test Procedure - The system is first evacuated to remove adsorbed fluids from the core, and then the core is saturated with methane at test pressure. The purpose of methane saturation is to allow adsorption of methane on the rock surface. When the pressure stabilizes, methane is displaced by injecting enough PV of the test fluid to saturate the core with test fluid. At the beginning of each test the piston of the pump is at its top position. The mixture is then expanded by reversing the piston pump at a constant rate. Eluid - A mixture of $C_{1} / C_{3}-15.125$ mole $\% C_{1}$, and 84.875 mole $\% C_{3}$ was used in the tests to be described next. The calculated bubblepoint pressure of this mixture at $770 \mathrm{~F}$ is 478 psia (from the PR-EOS).

\section{RESULTS}

Two tests were performed. The only difference between these two tests is the expansion rate.

Test $1-300 \mu \mathrm{m}^{3} \mathrm{hr}$ Expansion Rate - In this test, the $C_{1} / C_{3}$ mixture at an initial pressure of 650 psia was expanded at a rate of $300 \mu \mathrm{m}^{3} / \mathrm{hr}$. The sleeve pressure was kept nearly constant at 800 psia. Fig. 2 shows the pressure vs volume expansion. The pressure declines rapidly to an expanded volume of $1.25 \mathrm{~cm}^{3}$. At this point, the pressure is about $468 \mathrm{psia}$. Then the pressure rises, indicating the evolution of the gas phase. After the volume has expanded to $2.8 \mathrm{~cm}^{3}$, the pressure declines linearly with time with the slope of about $-1.6 \mathrm{psi} / \mathrm{cm}^{3}$. 
A total of nine small patches of gas were observed to form simultaneously on the front half of the vertical rock face at the volume expansion of $1.5 \mathrm{~cm}^{3}$. These patches were evenly distributed across the core. The patches of gas were observed increasing in size from 1.52 to $2.57 \mathrm{~cm}^{3}$ volume expansion. During the expansion period, the patches of gas increased in size, connected and formed bigger patches until the whole vertical surface of the core was covered. Figure 3 shows the pictures from the front half of the core at volume expansions of $1.93 \mathrm{~cm}^{3}$ (Figs $3 \mathrm{a}$ and $3 \mathrm{~b}$ ), and at $2.24 \mathrm{~cm}^{3}$ (Figs $3 \mathrm{c}$ and 3d). These pictures were taken about 1 1/2 (Figs $3 a$ and $3 b$ ) and $21 / 2$ (Figs $3 c$ and 3d) hours from the time the gas patches appeared on the surface of the rock. Note that the gas pattern in Figs. 3c and 3d has grown considerably at the later time (the darker region on the core surface represents gas phase). It should be pointed out that there were gas patterns in the horizontal direction but the angle that the camera was positioned precluded taking pictures from the exposed surface. We did not try to observe gas formation and growth on the back half of the vertical rock face.

At the volume expansion of $2.59 \mathrm{~cm}^{3}$, a filament of gas bubbles was observed flowing out of the top horizontal face of the core into the open space of the top endpiece. From 2.59 to $2.74 \mathrm{~cm}^{3}$ expansion (about half an hour), 13 bursts of gas filaments was observed flowing out of the core. The duration of burst of bubbles varied from 0.70 to 0.93 seconds. One hour after the first string of the gas filament was observed (i.e., 2.89 $\mathrm{cm}^{3}$ volume expansion), the time interval between burst of gas bubbles was about 1.5 minutes. For the remaining of this test, there were approximately 40 to 44 bursts of bubbles per hour. The duration of each burst of gas bubbles varied from 0.7 to 1.3 seconds, but the duration for most bursts was 0.77 to 1 seconds. All the bursts came from a single location on the core surface outlet. At a volume expansion of $8.9 \mathrm{~cm}^{3}$, the manner in which gas bursts out of the core is shown in Fig. 4. The top picture corresponds to the moment prior to gas flow. In the bottom two pictures, the bright filament of gas above "93" mark shows the form of the gas flow. At volume expansion of 
$8.9 \mathrm{~cm}^{3}$, the gas had completely filled the dead space of about $6 \mathrm{~cm}^{3}$ above the open space, and we could observe the appearance of gas at the top of the open space. Therefore, at this point gas saturation in the core could not exceed 2 percent. At the termination of the experiment, the gas nearly filled the open space at the top. At this point, the gas volume in the core and the pump is around $2.7 \mathrm{~cm}^{3}$. This test clearly shows that the critical gas saturation is very low, around 1 percent of pore volume.

At the termination of the test (i.e., when the pump was stopped), we measured a pressure increase of 2.5 psia indicating a supersaturation of 2.5 psia, This pressure increase realized in 5 hours. Fig. 2 shows that initially supersaturation is higher -- as expected -- and later it decreases. The calculated pressure-expansion in Fig. 2 is from the Peng-Robinson equation of state (PR-EOS).

Test $2-60 \mu \mathrm{m}^{3} \mathrm{hr}$ Expansion Rate - In Test 2 , the expansion rate was five times lower than Test 1 at $60 \mu \mathrm{m}^{3} / \mathrm{hr}$. The fluid mixture in the core was initially at 650 psia and the sleeve pressure at about 800 psia. Fig. 2 shows the pressure vs volume expansion from a pressure of around 595 psia. Prior to gas evolution, Tests 1 and 2 have nearly identical expansion behavior. Around an expansion volume of $1.2 \mathrm{~cm}^{3}$, the slope of the pressureexpansion volume changes. From expansion of 1.2 to $2.8 \mathrm{~cm}^{3}$, the pressure has an increasing trend. Thereafter, the pressure reduces nearly linearly with a slope of about $1.1 \mathrm{psi} / \mathrm{cm}^{3}$.

Visual observation of the core surface revealed gas forming first at one spot $2 \mathrm{~cm}$ from the bottom face of the core at $1.36 \mathrm{~cm}^{3}$ volume expansion. The surface area which the first patch covered increased to about $15 \mathrm{~mm}^{2}$ at volume expansion of $1.4 \mathrm{~cm}^{3}$. The area expanded to about $30 \mathrm{~mm}^{2}$ at $1.42 \mathrm{~cm}^{3}$ expansion. The patch grew in a path upwards around the core and its width increased with time. At around $1.42 \mathrm{~cm}^{3}$ expansion, another patch of gas appeared about $5 \mathrm{~cm}$ from the bottom face of the core. The first patch continued to "snake" around the core and at $1.5 \mathrm{~cm}^{3}$ expansion; it had a distance of about $8 \mathrm{~cm}$ from the top face of the core and $1 \mathrm{~cm}$ from the bottom face. It is 
likely that only one gas bubble was formed initially in this test. The second patch could be due to the growth of the first patch.

The first flow of gas from the core was observed at $1.84 \mathrm{~cm}^{3}$ expansion. During the first hour (from 1.84 to $1.90 \mathrm{~cm}^{3}$ ) four bursts of gas bubbles were observed. The duration of the gas bubble burst lasted from 0.8 to 1.2 seconds. For the remainder of the test, there were about 9 bursts of gas bubbles per hour. The duration of each burst of gas bubbles varied from 0.73 to 1.03 seconds, but mostly from 0.83 to 1.0 seconds. Similar to Test 1 , all the gas bubbles flowed from the same point of the core top face. The data for Test 2 reveal that critical gas saturation for the low expansion rate of $60 \mu \mathrm{m}^{3} / \mathrm{hr}$ is around 0.5 percent.

At the termination of Test 2, we continued to measure the pressure. There was no pressure increase, indicating negligible supersaturation. Fig. 2 also demonstrates that after volume expansion of $4.5 \mathrm{~cm}^{3}$, the supersaturation is negligible.

\section{DISCUSSION AND CONCLUSIONS}

The temperature control of $\pm 0.3^{\circ} \mathrm{F}$ could be improved. This is expected to affect the initial supersaturation of Fig. 2. We have to make some duplicate runs to establish test reproducibility. The main conclusions from the measurements are:

1 - Critical gas saturation is very low for low-viscosity light-fliuids -- less than 0.5 percent to for the test conditions of this report.

2 - Gas bubbles do not flow prior to considerable growth.

3 - Critical gas saturation is a measurable property. After the first onset of gas flow, pattern of gas flow romains the same. 


\section{REEERENCES}

1 - Loughead, D.J. and Saltuklaroglu, : "Lloydminster Heavy Oil Production - Why so unusual", Paper presented at the ninth annual Heavy Oil and Oil Sand Technology Symposium, Calgary, March 11, 1992.

2 - Maini, B.B., Sarma, H.K., and George, A.E.: "Significance of Foam-Oil Behavior in Primary Production of Heavy Oils", Paper No. CIM 92-77, presented at the CIM 1992 Annual Technical Conference, Calgary, June 7-10, 1992.

3 - Firoozabadi, A. and Kashchiev, D.: "The Evolution of Gas Phase in Solution GasDrive Process", SPE 26286 (paper in review).

4 - Firoozabadi, A., Ottesen, B., and Mikklosen, M.: "Measurement of Supersaturation and Critical Gas Saturation", SPE Formation Evaluation J. (Dec. 1992) 337-344.

Fig. 1 - Critical Gas Apparatus

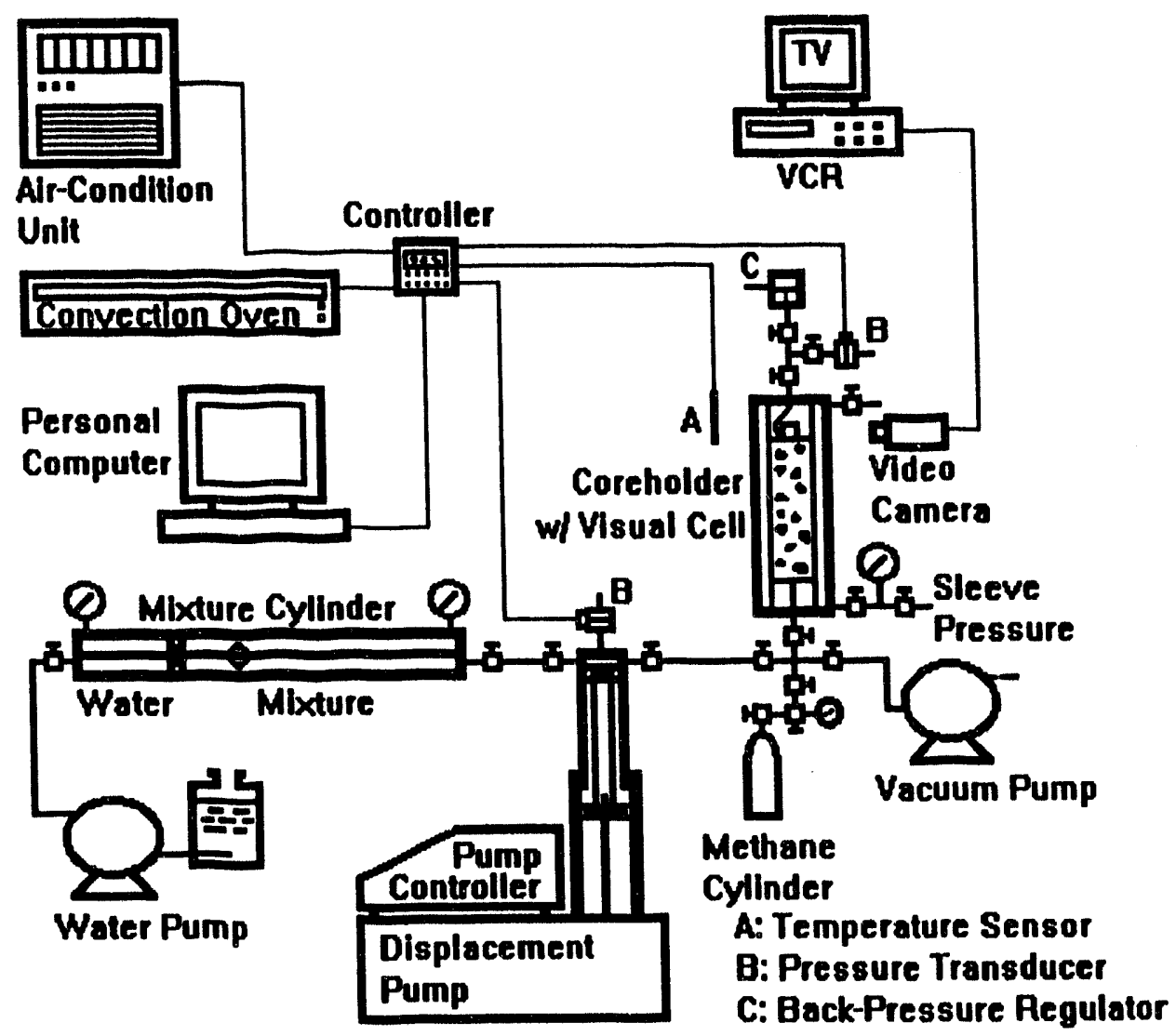


Fig. 2 - Pressure versus Volume Expansion for Tests land 2.

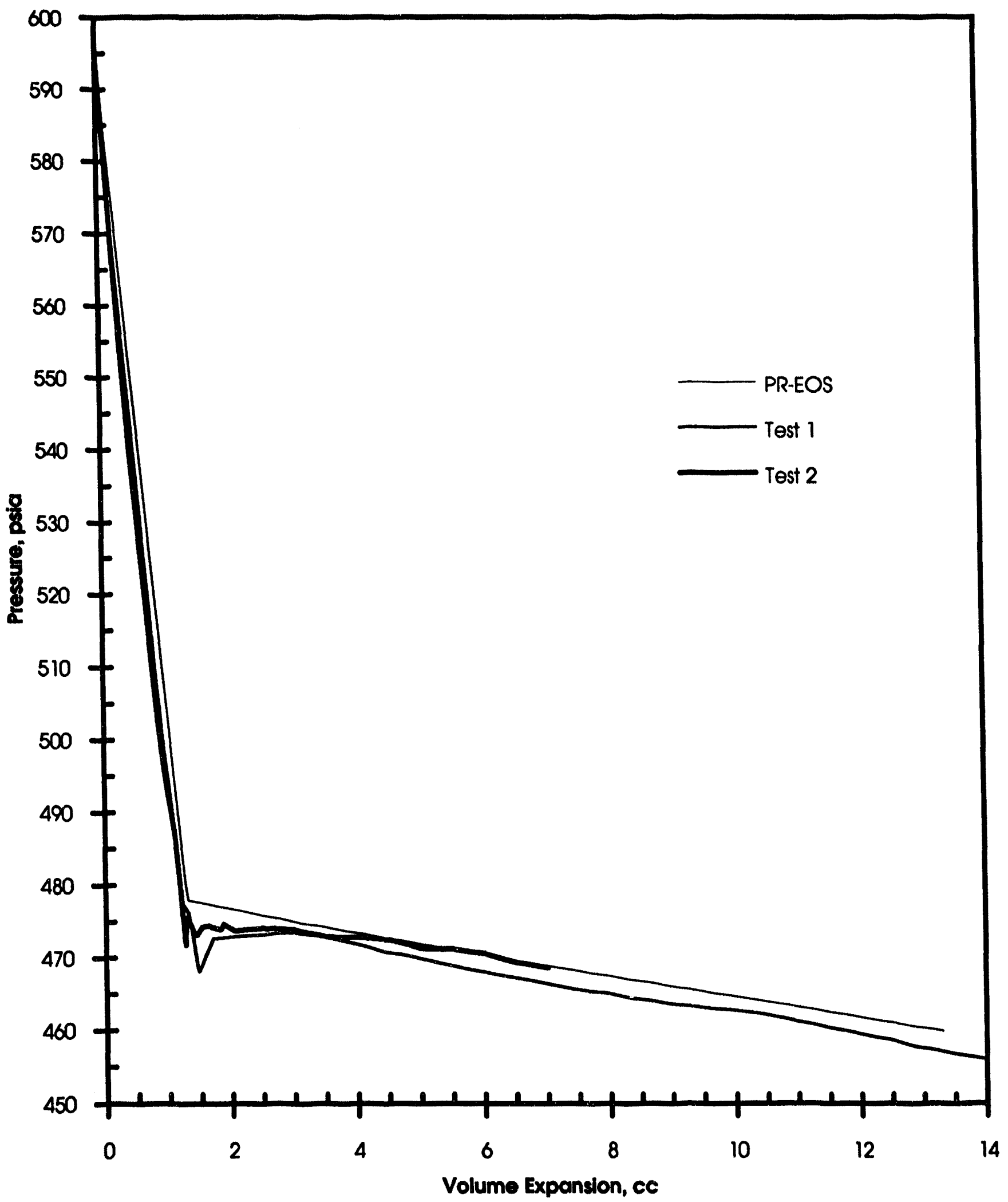




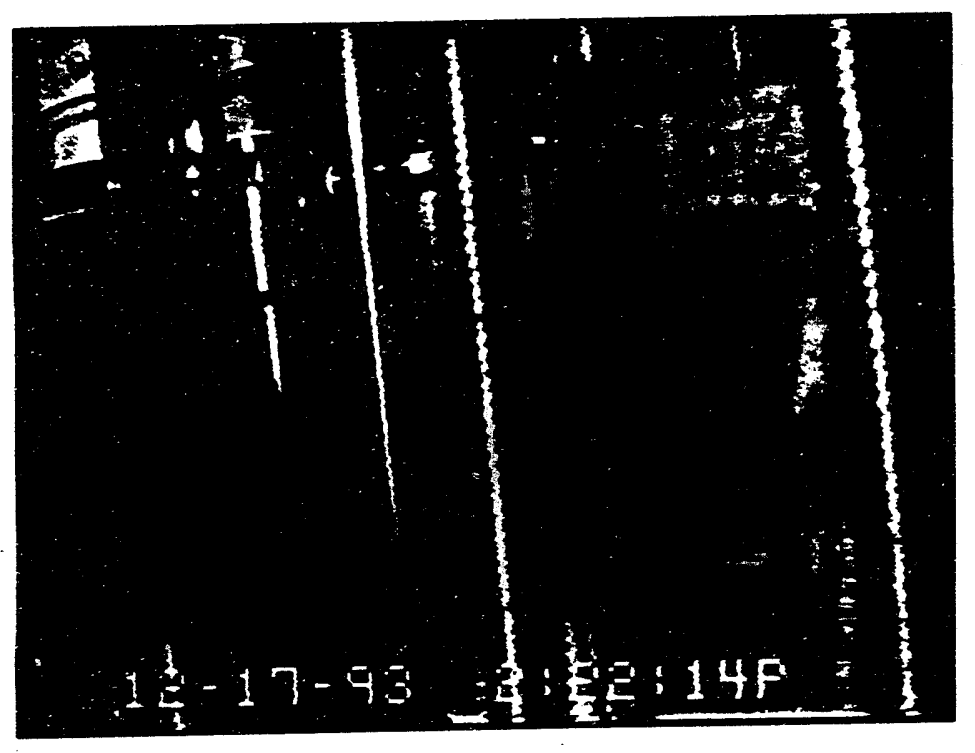

a) $\mathrm{VE}=1.93 \mathrm{~cm}^{3}$

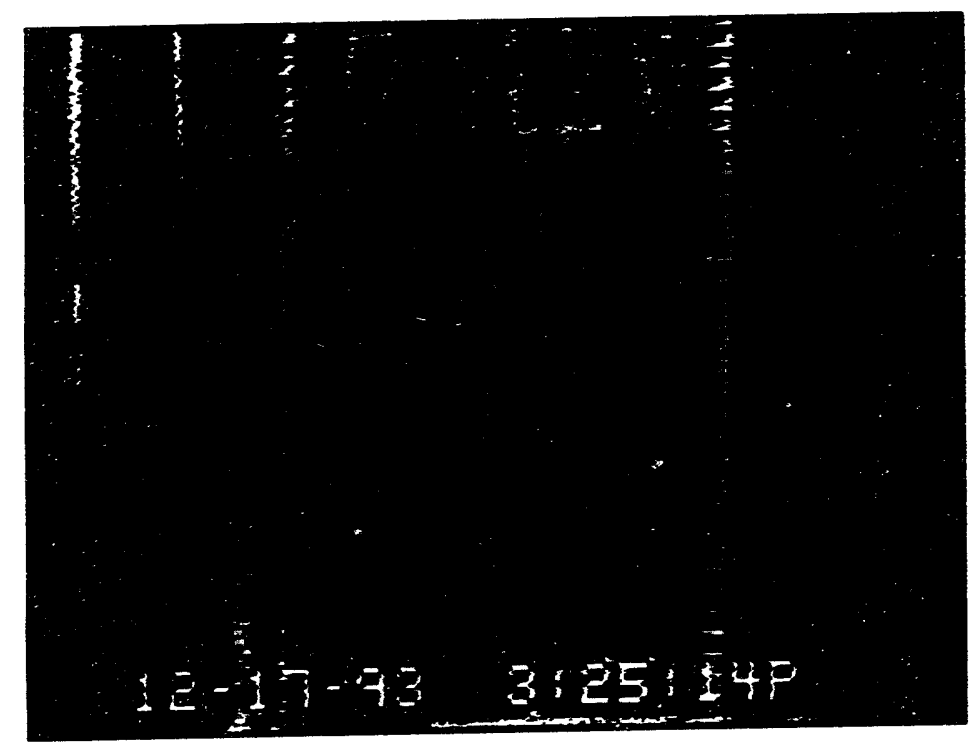

c) $\mathrm{VE}=2.24 \mathrm{~cm}^{3}$

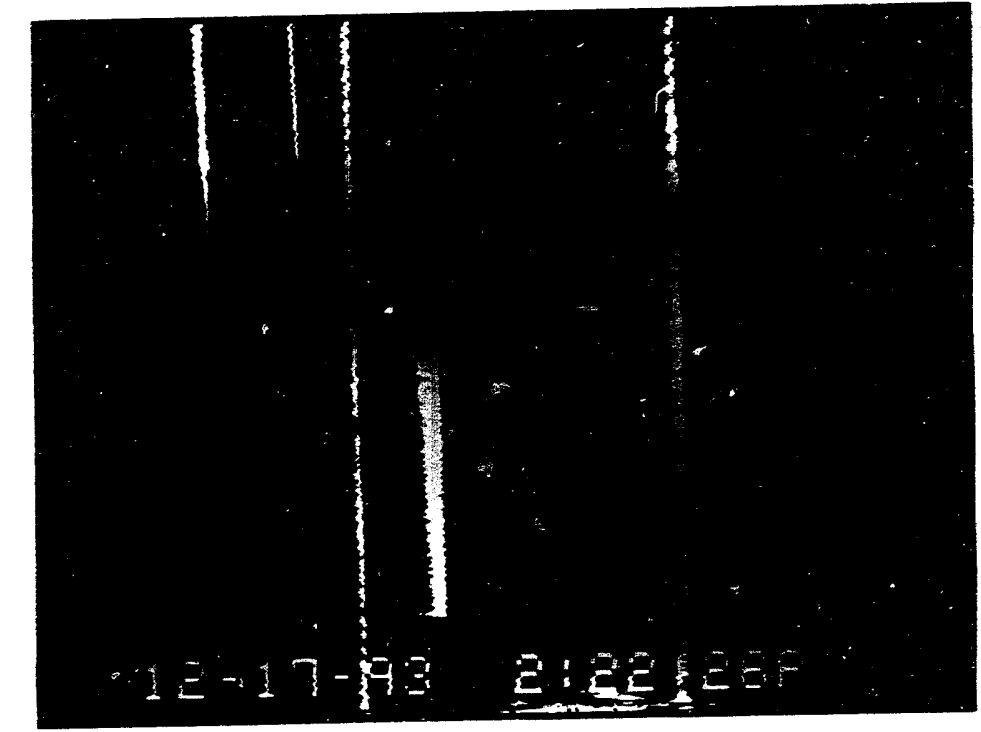

b) $V E=1.93 \mathrm{~cm}^{3}$

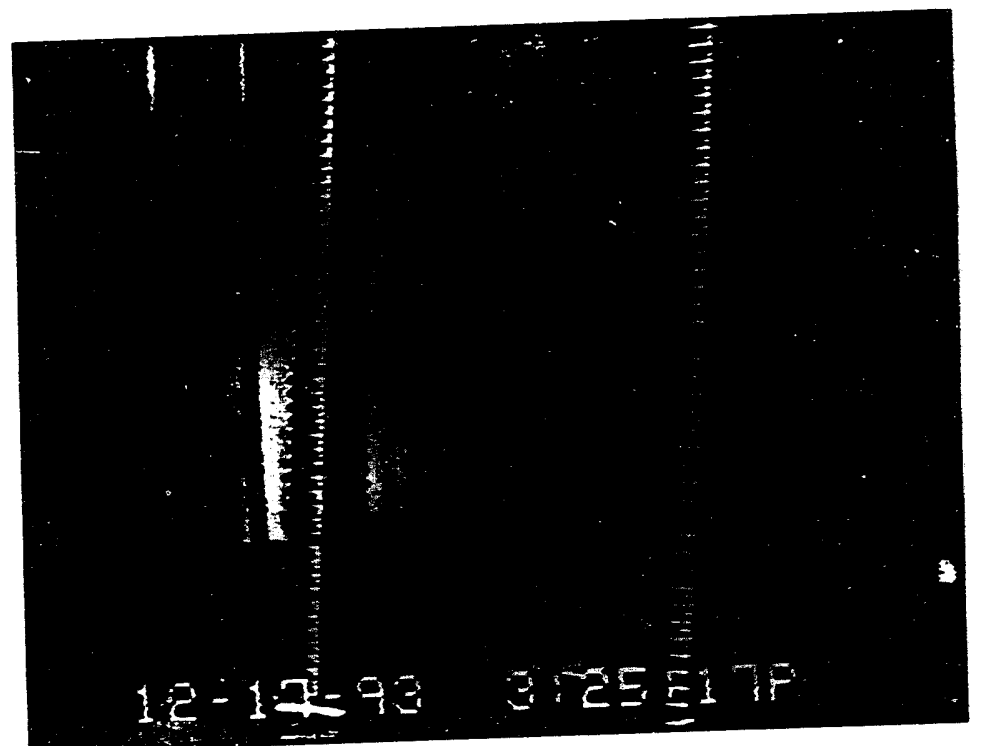

d) $\mathrm{VE}=2.24 \mathrm{~cm}^{3}$

Fig. 3 - Pattern of gas growth on the core surface for Test 1. 

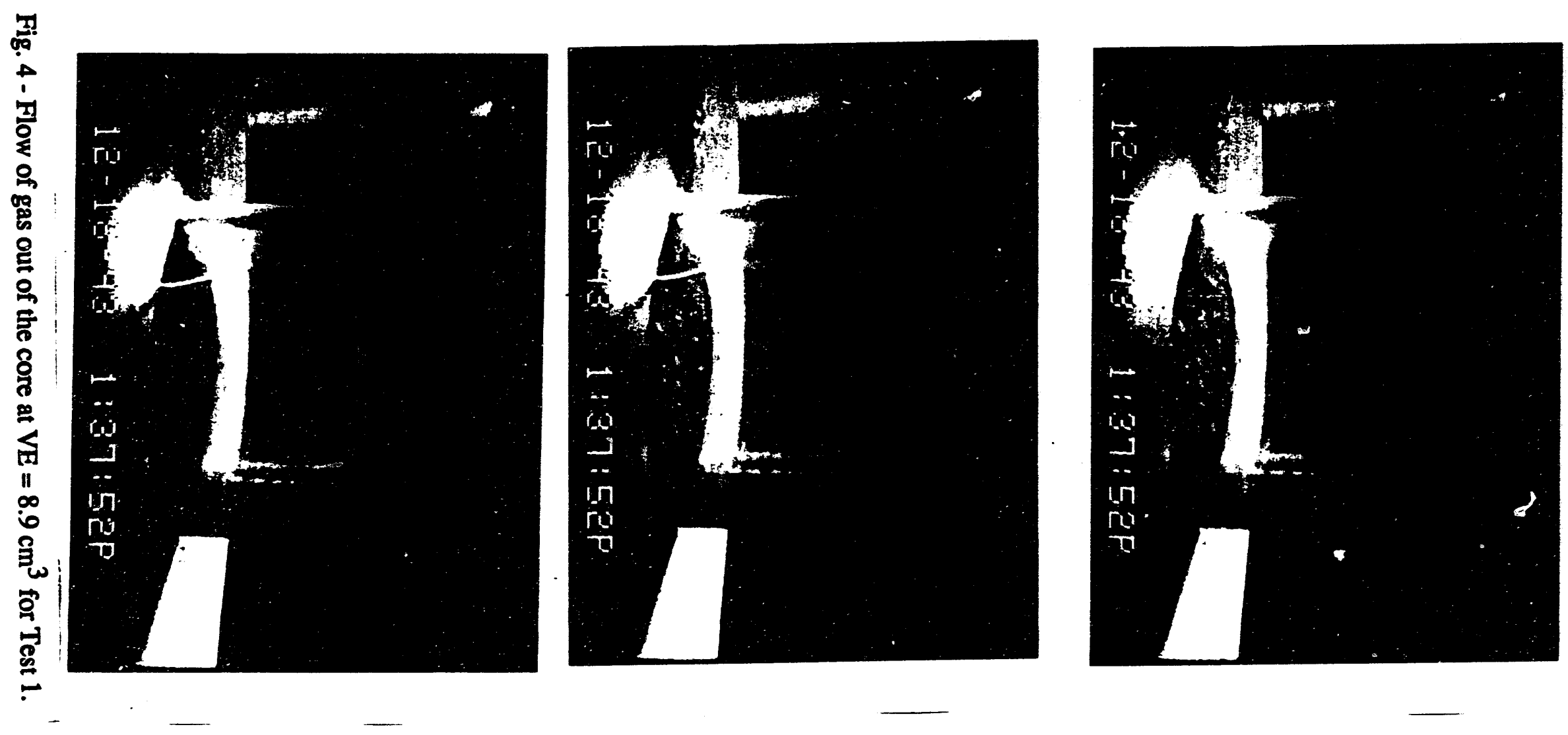

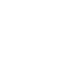




\section{RESERVOIR ENGINEERING RESEARCH}

INSTITUTE

PROJECT 5 - SIMULATION OF FRACTURED RESERVOIRS

\section{DUAL-POROSITY SIMULATION INCORPORATING REINFILTRATION AND CAPILLARY CONTINUITY CONCEPTS \\ PART I: REINFILTRATION IN A COMPUTATIONAL GRID CELL}

$4 Q .93$

October 1, through December 31, 1993 


\section{DUAL-POROSITY SIMULATION INCORPORATING REINFILTRATION AND \\ CAPILLARY CONTINUITY CONCEPTS - PART 1 : REINFILTRATION IN A COMPUTATIONAL GRID CELL}

\section{SUMMARY}

We have developed a method to account for reinfiltration in a grid cell that may contain a large number of matrix blocks. The proposed method requires fine grid simulation of a two-block stack. Using the same fine grid simulation results, a scaling procedure is proposed to account for the variation of capillary pressure during the course of depletion.

\section{INTRODUCTION}

It is generally recognized that in fractured porous media, the reinfiltration (reimbibition) of drained oil from some matrix blocks to the neighboring blocks in the gas-oil two-phase region could have an important effect on the drainage performance ${ }^{1-4}$. It has also been demonstrated that capillary continuity (i.e., oil phase pressure continuity) between matrix blocks (with fractures between them) has a significant effect on oil recovery performance and GOR behavior 5,6 . Reinfiltration is due to the capillary and gravity forces 7 , and capillary continuity is related to the fracture capillary pressure 6 . The understanding of both processes has set the stage for their incorporation in dual-porosity fractured models. Two recent papers discuss the modification of dual-porosity models to account for reinfiltration and capillary continuity. We will first review these papers.

Fung 8 included reinfiltration in a computational grid cell of a dual-porosity reservoir simulation that contains a stack of matrix blocks. He first refined the grid into the level of individual matrix block, then adopted a dual-porosity approach to calculate the drainage performance of the entire stack (computational grid cell). In the model, the reinfiltration effect is taken into account by allowing the communication between each fracture and the matrix block below. The amount of reinfiltration is characterized by a fractional 
reinfiltration parameter, $\beta$. Once the drainage rate versus the average stack saturation is obtained, the information is then applied to construct a pseudo-capillary pressure curve for the full scale reservoir simulation. Fung showed a reasonable agreement between his model and the detail simulation results. The deficiencies in Fung's approach are: 1) the assumption that drainage rate of every matrix blocks in the stack is a simple function of the average matrix block saturation (this assumption may not be valid as we will see this issue later in this report), 2) when $\beta<1$, one has to perform fine grid simulations to obtain this parameter, (3) the model may not be valid for a stack of blocks with non-uniform matrix block properties, 4) the model does not "dynamically" take into account the change of drainage rate with capillary pressure change; one has to construct the pseudo-capillary pressure curves at various pressures (interfacial tension effect) for every grid cells by using the detailed simulations, and 4) dual-permeability concept is used to account for capillary continuity which may not be a proper approach.

Por, et al..$^{9}$ applied a different approach. To account for the effect of reinfiltration, they introduced additional connections between matrix and fracture nodes. Connectiondependent relative permeabilities were used to prohibit flow in the fractures when fracture oil saturation is below a certain threshold. Similar to Fung, Por, et al. used the dualpermeability approach for matrix blocks with capillary contact. Deficiencies associated with their model are: 1) the reinfiltration is only taken into account between the computational grid blocks but not within the grid block, unless each computational grid represents a single matrix block, 2) it is not clear how matrix-fracture relative permeabilities were obtained, probably through detailed simulation results. This process requires simulations for every grid cells, and 3) reinfiltration is assumed to be entirely driven by the gravity potential, which neglects capillary pressure driving force.

Based on the above review, it is clear that although some attempts were made to resolve issues of reinfiltration and capillary continvity, the problems have not been solved completely. 
The objective of this work is to provide a simple method to model the reinfiltration process in the simulation of gas-oil drainage in fractured porous media. Our current effort is to develop a scheme that can accurately describe the drainage performance of a single computational grid cell that is used for the dual-porosity simulation. A computational grid can consist of only one matrix block, but it is usually composed of a stack of many matrix blocks. Future work includes accounting of capillary continuity between matrix blocks in a stack within a grid cell, and capillary continuity and reinfiltration between grid cells in a dual-porosity model.

\section{PROPOSED MODEL}

Through the examination of saturation behavior of various blocks in a stacked-block system, we have found that there is a correlation between the drainage rate and the individual matrix average saturation. For the purpose of illustration, the analytical model of Firoozabadi and Ishimoto ${ }^{3}$ will be used to investigate the variation of drainage rate versus average saturation of individual blocks in a stack. In this example, all matrix blocks are assumed to be $60 \mathrm{~cm}$ in height, have a permeability of 0.7 darcy, porosity of $22 \%$, and cross-sectional area of $225 \mathrm{~cm}^{2}$. Fracture permeability is 100 darcy. The density difference between the oil and gas phases is assumed $0.724 \mathrm{~g} / \mathrm{cm}^{3}$, and the oil viscosity is assigned a value of $0.866 \mathrm{cp}$. The analytical model of Ref. 3 is based on, 1) infinite gas mobility, 2) incompressible gas and oil phases, and 3) zero fracture capillary pressure. The oil relative permeability and the gas-oil capillary pressure are expressed by $\mathrm{k}_{\mathrm{ro}}=\mathrm{C}_{\mathrm{o}}\left(1-\mathrm{S}_{\mathrm{g}}\right)$, and $P_{c}=-P_{c o} \ln \left(1-S_{g}\right)$, respectively. In this illustration, we assign $C_{0}=1$, and $P_{c 0}=0.15$ psi. The symbols are defined in Nomenclature.

Both fine grid simulations and the concepts advanced in Ref. 3 reveal that oil drained from the upper matrix blocks will completely reinfiltrate into the lower blocks. The rate of drainage of each matrix block in a stack of $\mathbf{N}$ identical blocks (the case of non-identical blocks will be considered later in this report) is given by 


$$
\begin{aligned}
& q_{1}=-\phi h \frac{d \bar{S}_{g_{1}}}{d t} \\
& q_{2}=-\phi A h\left(\frac{d \bar{S}_{g^{2}}}{d t}\right)+q_{1} \\
& \vdots \\
& q_{N}=-\phi \operatorname{Ah}\left(\frac{d \bar{S}_{g N}}{d t}\right)+q_{N-1}
\end{aligned}
$$

In the above equation, $\bar{s}_{g i}$ is the average gas saturation and $q_{i}$ is the drainage rate of block i. Both $\bar{S}_{g i}$ and $\mathrm{q}_{i}$ are function of time, $t$.

We used the solution techniques of Ref. 3 to calculate $\bar{S}_{g i}$ analytically. Then Eq. 1 was employed to calculate $\mathrm{q}_{\mathrm{i}}$. The normalized drainage rate, $\mathrm{q}_{\mathrm{i}} / \phi \mathrm{Ah}$, versus $\bar{S}_{g i}$ is plotted in Fig. 1 for $N=10$. Note that $\phi A h$ is the pore volume (PV) of each matrix block. The figure reveals that each matrix block in a stack has a drainage behavior that is different from the others. The difference is particularly large between the first block and the rest. However, we observe that drainage behavior for blocks $i \geq 2$ is generally similar. Therefore, we may approximate the drainage rate for all blocks in a stack by using only two drainage curves in Fig. 1: 1) the drainage curve for the first block where reinfiltration is absent, and 2) the drainage curve for the rest of the blocks (represented by the drainage curve of the second block in Fig. 1) where there is reinfiltration. Such an approach requires that the drainage rate and saturation behavior for blocks 2 to $\mathrm{N}$ to be the same. We shall demonstrate next by simply using the two drainage curves that one can accurately construct the drainage performance of the entire stack of $\mathrm{N}$ blocks.

Let us define the relationship between the drainage rate and the block average gas saturation for the two cases (without and with reinfiltration of oil) to be $F_{1}\left(\bar{S}_{8}\right)$ and $F_{2}\left(\bar{S}_{8}\right)$. We use $F_{1}$ to calculate the drainage rate of the first block and $F_{2}$ for the rest of the blocks, then Eq. 1 becomes: 


$$
\begin{aligned}
& \frac{d \bar{S}_{81}}{d t}=\frac{-1}{\phi A h} F_{1}\left(\bar{S}_{81}\right) \\
& \frac{d \bar{S}_{82}}{d t}=\frac{-1}{\phi A h} F_{2}\left(\bar{S}_{82}\right)+\frac{d \bar{S}_{81}}{d t} \\
& \vdots \\
& \frac{d \bar{S}_{8 N}}{d t}=\frac{-1}{\phi A h} F_{N}\left(\bar{S}_{8 N}\right)+\frac{d \bar{S}_{8(N-1)}}{d t}
\end{aligned}
$$

where $F_{i}=F_{2}$ for $i \geq 2$. Integrating Eq. 2 with time enables us to calculate the average saturation versus time for all the blocks and thus the drainage rate of the entire stack.

Fig. 2 compares the cumulative production (normalized by the total PV) calculated from the analytical solution of Ref. 3 and our proposed model using the first and second drainage curves of Fig. 1. For all three cases with $\mathrm{N}=3,5$, and 10 (Figs. 2a, 2b, and 2c), the agreement is excellent. The comparison of the results for average gas saturation versus time for individual blocks of the 10 block-stack is shown in Fig. 3. The agreement between the analytical solution and our model is excellent for blocks 1, 3 and 5 and is fair for the tenth block. Further validation will be presented later.

Here, we summarize the procedure to model the drainage performance of a stack of blocks with reinfiltration effect:

a) Based on the detailed numerical simulation of a stack of two blocks, drainage rate versus $\bar{S}_{8}$ relationship is established. $F_{1}$, and $F_{2}$ curves represent zero reinfiltration and reinfiltration, respectively

b) Eq. 2 is applied to calculate $\bar{S}_{g i}$ versus time.

c) The total material balance equation is used to obtain the drainage rate versus $\bar{S}_{g}$ for the stack of $\mathbf{N}$ matrix blocks, and

d) The information in step (c) is used to calculate the drainage behavior of a grid cell in the dual-porosity simulation model which contains a stack of $\mathrm{N}$ blocks. 


\section{MODELVALIDATION}

A number of cases are considered to compare fine grid simulation results with the above proposed model. Unless stated otherwise, a stack of ten blocks comprise a single numerical grid. The fluid properties, matrix porosity and permeability, and areal dimensions are the same as those used in our illustrative example. The relative permeability and the gas-oil capillary pressure for the matrix are:

$$
\begin{aligned}
& k_{\text {rom }}=\left(\frac{S_{\text {om }}-S_{\text {orm }}}{1-S_{\text {orm }}}\right)^{3.5} \\
& P_{c m}=P_{c m}^{o}-\sigma_{m} \ln \left(\frac{S_{\text {om }}-S_{\text {orm }}}{1-S_{\text {orm }}}\right)
\end{aligned}
$$

with $S_{\text {orm }}=0.26$. For the fracture, we assume $k_{\text {rof }}$ changes linearly with $S_{o f}$, and the fracture capillary pressure is zero. In Eqs. $4, P_{c m}^{o}$ is the threshold capillary pressures of the matrix. Dindoruk and Firoozabadi: 10 used the above capillary pressure and relative permeability expressions to successfuily simulate the experimental data for a single matrix block drainage test 11 . We have adopted the same equations for relative permeability and capillary pressure. All our simulations were conducted on an Apollo workstation by using the Eclipse ${ }^{12}$ reservoir simulator. We used ten grids for each matrix block for $\mathrm{h}=60 \mathrm{~cm}$ and twenty grids for $\mathrm{h} \succeq 180 \mathrm{~cm}$. These grid numbers per matrix block are adequate to correctly describe the saturation profile and drainage rate. In what follows, various cases are presented.

\section{Case liddentical Blocks (h=60 cm)}

In this case, $\mathrm{h}=60 \mathrm{~cm}, P_{c m}^{o}=0.4 \mathrm{psi}, \sigma_{\mathrm{m}}=-0.17 \mathrm{psi}$. A threshold matrix capillary pressure of $0.4 \mathrm{psi}$ is equivalent to a $38.8 \mathrm{~cm}$ gravity head $\left(\Delta \rho=0.724 \mathrm{~g} / \mathrm{cm}^{3}\right)$. The equilibrium gas saturation $\mathrm{S}_{\mathrm{ge}}$ (average block gas saturation at $\mathrm{t} \sim \infty$ ) is calculated to be 0.114 for all the blocks. 
Fig. 4 shows the normalized drainage rate $\left(q_{i} / \phi A h\right)$ versus $\bar{S}_{\mathfrak{d}}$ for the first four blocks. It is interesting to note that except for the first block, all other blocks have a very similar drainage behavior. We used the drainage curves from the first and second blocks in Fig. 4 (which are similar in this case), and applied Eq. 2 to calculate the gas saturation for each block. Comparison of $\bar{S}_{8}$ from the model prediction and the numerical simulation is shown in Fig. 5. Results indicate that there is an excellent agreement between the two methods. In Fig. 5b, we also plot the saturation history under the condition of zero reinfiltration. The difference is significant.

\section{Case 2: Identical Blocks $(\mathrm{h}=180 \mathrm{~cm})$}

The only difference between Case 2 and Case 1 is the increase in block height from 60 to $180 \mathrm{~cm}$. The equilibrium gas saturation is the same for all the blocks and is equal to 0.513 .

Fig. 6 shows the drainage rate versus $\bar{S}_{8}$ for the individual blocks. The figure indicates that unlike Case 1, the drainage curve for the first block in Case 2 is very different from the other blocks. It also demonstrates the importance of using the second drainage curve in our model calculations. In Fig. 7, we compare results from our model prediction with detailed numerical simulation; a good agreement is evident. Notice that in Case 2 (see Fig. 7b), the effect of neglecting the reinfiltration of oil is more pronounced than that of Case 1 (see Fig. 5b), indicating that the influence of block height.

\section{STACKED-BLOCKS WITH NON-UNIFORM MATRIXPROPERTIES}

When matrix blocks in a stack have different properties (i.e., different permeabilities, heights, etc.), the assumption of complete reinfiltration may no longer be valid, and the more general form of Eq. 1 becomes, 


$$
\begin{aligned}
& q_{1}=-\phi_{1} A_{1} h_{1} \frac{d \bar{S}_{11}}{d t} \\
& q_{2}=-\phi_{2} A_{2} h_{2}\left(\frac{d \bar{S}_{12}}{d t}\right)+R_{1} \\
& \vdots \\
& q_{N}=-\phi_{N} A_{N} h_{N}\left(\frac{d \bar{S}_{N}}{d t}\right)+R_{N-1}
\end{aligned}
$$

In the above equation, $\mathbf{R}_{\mathbf{i}}$ is the oil reinfiltration rate to the block $(i+1)$. We scale the drainage rate linearly to the permeability $k$, so that

$$
q_{i}=\frac{k_{1}}{k^{*}} q_{i}
$$

where $q_{i}^{*}$ is the drainage rate of matrix block $i$ in a homogeneous stack with a permeability $k^{\bullet}$, and $q_{i}^{*}$ therefore is the same as $F_{i}$. Combining Eqs. 5 and 6 ,

$$
\begin{aligned}
& \frac{d \bar{S}_{t 1}}{d t}=\left(\frac{-k_{1}}{\phi_{1} A_{1} h_{1} k^{*}}\right) F_{1}\left(\bar{S}_{t_{1}}\right) \\
& \frac{d \bar{S}_{\ell^{2}}}{d t}=\left(\frac{-1}{\phi_{2} A_{2} h_{2}}\right)\left[\frac{k_{2}}{k^{*}} F_{2}\left(\bar{S}_{22}\right)-R_{1}\right] \\
& \vdots \vdots \\
& \frac{d \bar{S}_{t N}}{d t}=\left(\frac{-1}{\phi_{N} A_{N} h_{N}}\right)\left[\frac{k_{N}}{k^{*}} F_{N}\left(\bar{S}_{g N}\right)-R_{N-1}\right]
\end{aligned}
$$

The next step is to determine the reinfiltration rate, $\mathbf{R}_{\mathbf{i}}$ in Eq. 7. A conservative approach to include reinfiltration in our model would be to assume that the rate of reinfiltration to any block is always equal to the initial (i.e., maximum) drainage rate for that particular block ${ }^{3}$. If the rate of drainage of block $i, q_{i}$, is less than the oil flow rate coming from above, only portion of the incoming oil will reinfiltrate to block $i$. Mathematically, we can define:

$$
r_{i+1}=\sum_{j=1}^{i}\left(q_{j}-R_{j}\right)
$$


where $r_{i+1}$ is the oil rate bypassing matrix block $(i+1)$ which could be zero. Then we can write,

$$
\begin{aligned}
& R_{t}=q_{i}+r_{i}, \text { if }\left(q_{i}+r_{i}\right) \leq q_{i+1}^{i} \\
& R_{i}=q_{i+1}^{i}, \text { if }\left(q_{i}+r_{i}\right)>q_{i+1}^{i}
\end{aligned}
$$

In Eq. 9, $q_{i+1}$ is the initial (maximum) rate of drainage of block ( $\left.i+1\right)$. Eqs. 7 through 9 complete the formulation. The fullowing two cases for non-uniform matrix blocks validate the above model. The matrix block data for the two cases are sketched in Fig. 8.

\section{Case 3: Non-Uniform Permeability}

This four stacked-block system has a permeability $k=0.7$ darcy for the first and the third blocks, and $k=0.1$ darcy for the second and fourth blocks (see Fig. 8). Other properties are similar to Case 2 . We first set $q_{1}^{*}=\mathrm{F}_{1}\left(\bar{S}_{81}\right)$, and $q_{i}^{*}=\mathrm{F}_{2}\left(\bar{S}_{g i}\right), \mathrm{i} \geq 2$, where $\mathrm{F}_{1}$ and $\mathrm{F}_{2}$ are the drainage functions for $\mathbf{0 . 7}$ darcy matrix blocks of the first and second blocks of Case 2 , respectively. Eqs. 7-9 are then applied to calculate the saturation history for each block. The agreement between the model prediction and the detailed simulation results are very good (see Fig. 9). Note that the average gas saturation in the stack matches almost perfectly with the fine grid simulation results.

\section{Case 4: Non-Uniform Permeability and Height}

In Case 4, different heights and permeabilities are assigned for each block in a stack of six blocks (see Fig. 8). Matrix capillary pressure is kept the same for all the blocks and fracture capillary pressure is assigned zero.

The drainage curves from the simulation of homogeneous stacked-blocks for Case 1 (second curve) and Case 2 (first and second curves) are used, and then Eqs. 7-9 are applied to solve for the saturation history. Results shown in Fig. 10 indicate that our model not only matches the drainage performance of the whole stack, but the saturation history of the individual blocks as well.

\section{SCALING}


So far we have assumed that gas-oil capillary pressure does not vary with pressure and that all the matrix blocks have the same capillary pressure. Matrix capillary pressure is generally a function of both permeability and the reservoir pressure (the effect of pressure on gas-oil capillary pressure is through gas-oil surface tension dependency on pressure). We thus wish to find a proper scale for the drainage rate so that we can reduce the number of the detailed simulations that are required for our model. Coats 12 proposed that for the drainage of a single matrix block, since the initial drainage rate is proportional to ( $\Delta p g$ $P_{c m}^{o}(\mathrm{~h})$ and the average gas saturation of the block approaches $S_{g e}$ at an infinite time, one might be able to scale the drainage rate and the matrix block saturation with ( $\Delta p g$ $P_{c m}^{o} / \mathrm{h}$ )and $\mathrm{S}_{g e}$ to obtain a similar form of solution for the block saturation history. To verify this proposal, we performed fine grid simulations for the drainage of 1) a single block and 2) four stacked-block systems. We varied block heights and coefficients of capillary pressure expression in Eq. 4. Let us define

$$
S_{8}^{+}=\frac{\bar{S}_{8}}{S_{8 e}}
$$

and

$$
t^{+}=t \frac{\left(\Delta \rho g h-P_{c m}^{o}\right)^{*}}{\left(\Delta p g h-P_{c m}^{o}\right)}
$$

Superscript "*" refers to data of the reference state. Fig. 11 depicts $S_{g}^{+}$versus $\mathrm{t}^{+}$for a single block of the properties given in Case $2\left(\mathrm{~h}=180 \mathrm{~cm}, \mathrm{k}=0.7\right.$ darcy, and $\left.P_{c m}^{o}=0.4 \mathrm{psi}\right)$ as a reference state. The figure reveals that except for the two cases that have relatively large values of $P_{c m}^{o} / \Delta \rho g h$, all other results are fairly close to each other. The two deviated cases can be also identified as the cases that have a low equilibrium gas saturation. The equilibrium gas saturation values for all the cases are listed in Table 1. Considering such a wide variation in $S_{g e}$, the scaling of expressions given by Eqs. 10 and 11 provides a satisfactory approximation for the drainage performance of a single block system. We 
next extended the analysis to a stack of four blocks of reference properties of the above single block with zero fracture capillary pressure. Since there is no fracture capillary pressure, the equilibrium gas saturation for the stack is the same as that for the individual blocks, see Table 1. In Fig. 12, a similar behavior as that in Fig. 11 is observed; $s_{8}^{+}$versus $\mathrm{t}^{+}$of the total stack approximately falls on one curve if $P_{c m}^{o} / \Delta \mathrm{pgh}$ is small. We therefore postulate that, under the condition that there is no fracture capillary pressure, if the matrix blocks are tall or the threshold pressure is small, we can obtain a single relationship between $S_{8}^{+}$and $t^{+}$to approximate the drainage rate when there is a change of capillary pressure with reservoir pressure and block heights vary. This approach significantly reduces the number of detailed simulations required for each computational grid cell in dual-porosity models.

The next two examples illustrate how we can use the new scaling group to calculate the drainage performance of a stack of blocks of non-uniform properties.

\section{Case 5: Non-Uniform Permeability and Capillary Pressure, Constant Block Height}

The schematic of Case 5 is shown in Fig 13. The four blocks in the stack all have the same height but different permeabilities. The matrix capillary pressure is assumed to be inversely proportional to the square root of permeability, and fracture capillary pressure is assumed zero. Similarity expression is employed to approximate the drainage rate of each block, so that

$$
q_{1}=\frac{k_{i}}{k^{*}} \frac{\left(\Delta \rho g h-P_{m}^{o}\right)_{i}^{*}}{\left(\Delta p g h-P_{o m}^{o}\right)_{i}} \frac{h_{i}}{h^{*}} q_{i}^{*}\left(S_{i}^{+}\right)
$$

We then substitute Eq. 12 into Eq 5 to perform saturation calculations. Here, we chose the properties in Case 2 as reference state so that $q_{1}^{*}\left(S_{g 1}^{+}\right)=\mathrm{F}_{1}$, and $q_{i}^{*}\left(S_{g i}^{+}\right)=\mathrm{F}_{2}$, $\mathrm{i} \geq 2$, where $F_{1}$ and $F_{2}$ are the drainage functions for 0.7 darcy matrix blocks of the first and second blocks of Case 2, respectively.

Fig. 14 shows the comparison of saturation history between the model prediction and the detailed simulation. Excellent agreement between the two is indicated. 


\section{Case 6: Non-Uniform Permeability, Block Height, and Capillary Pressure}

The schematic of Case 6 is also shown in Fig 13. This is the most complicated case that we have studied, in which the six individual blocks in a stack have different heights and permeabilities. The capillary pressure in the matrix block is also assumed to be inversely proportional to the square root of block permeability, and fracture capillary pressure is zero.

Fig. 15 shows the comparison between the proposed model and the detailed simulation result. Due to the approximation that we employed for the drainage rate, we observe that the gas saturation predicted from our model is slightly higher for some matrix blocks. However, the overall agreement between the model and the simulation result is excellent.

\section{CONCLUSTON AND DISCUSSION}

In this study, we have developed a method to account for reinfiltration in a computational grid cell that is used for the dual-porosity simulations. This method, which is based on fine grid simulation result of a two-block stack, can accurately describe the drainage performance of a stack of $\mathrm{N}$-block system. This model has also been extended to a stack with non-uniform matrix block properties. With the proposed scalings of the drainage rate and time, we can approximate the drainage rate of matrix blocks with different heights and capillary pressures by using results of a single fine grid simulation of a two-block stack.

We are currently studying how to account for capillary continuity between the matrix blocks in a stack. A number of other issues are also under investigation. The goal of this research project is a dual-porosity model which could account for reinfiltration and capillary continuity between matrix blocks.

\section{NOMENCLATURE}

$$
\begin{aligned}
& A=\text { cross sectional area } \\
& \mathbf{g}=\text { gravity }
\end{aligned}
$$




$$
\begin{aligned}
& k=\text { permeability } \\
& h=\text { height } \\
& N=\text { total number of blocks in a stack } \\
& P_{c}^{o}=\text { threshold capillary pressure } \\
& q=\text { drainage rate per unit area } \\
& R=\text { reinfiltration rate per unit area } \\
& r=\text { net oil flow rate per unit area } \\
& S=\text { saturation } \\
& S_{g e}=\text { equilibrium gas saturation } \\
& S_{O r}=\text { residual oil saturation } \\
& \bar{S}=\text { average saturation in a matrix block } \\
& t=\text { time } \\
& \beta=\text { fractional reimbibition factor } \\
& \mu=\text { viscosity } \\
& \phi=\text { porosity } \\
& \rho=\text { density } \\
& \sigma=\text { capillary pressure coefficient in Eq. } 4
\end{aligned}
$$

Subscript

$$
\begin{aligned}
& f=\text { fracture } \\
& g=\text { gas } \\
& i=\text { the ith block } \\
& m=\text { matrix } \\
& o=\text { oil }
\end{aligned}
$$

\section{Superscript}

$$
\begin{aligned}
& *=\text { reference state } \\
& +=\text { scaled variables }
\end{aligned}
$$




\section{RETERTACES}

1. du Prey, E. L., "Cascade Drainage of Blocks in a Fissured Reservoir," Rev. Inst. Francais du Petrole (Jan.-Feb. 1976) 173-78.

2. Saidi, A. M., Tehrani, D.H., and Wit, K., "Mathematical Simulation of Fractured Reservoirs Performance Based on Physical Model Experiments," Proc. 10th World Petroleum Congress, Bucharest (1979) paper PD10 (3) 225-33.

3. Firoozabadi, A. and Ishimoto, K., "Theory of Reinfiltration in Fractured Porous Media Part 1: One Dimensional Model", SPE 21796, also SPE Advanced Technology Series (in press).

4. Firoozabadi, A. and Ishimoto, K., and Dindoruk, B., "Theory of Reinfiltration in Fractured Porous Media - Part 2: Two Dimensional Model", SPE 21798, also Advanced Technology Series (in press)..

5. Horie, T., Firoozabadi, A. and Ishimoto, K., "Laboratory Studies of Capillary Interaction in Fracture/Matrix System," SPE Reservoir Engineering Journal (August 1990) 353-360..

6. Firoo:zabadi, A, and Hauge, J., "Capillary Pressure in Fractured Porous Media," JPT (June 1990) 784-791.

7. Barkve, T., and Firoozabadi, A., "Analysis of Reinfiltration in Fractured Porous Media," paper SPE 24900 presented at the 1992 SPE Annual Technical Conference and Exhibition, Washington, DC, Oct. 4-7.

8. Fung, L. S.-K., "Simulation of Block-to-Block Processes in Naturally Fractured Reservoirs", SPE Reservoir Engineering, Nov. 1991, 477-484

9. Por, G. J., Boerrigter, P., Maas, J. G., and de Vries, A., "A Fractured Reservoir Simulator Capable of Modeling Block-Block Interaction", paper SPE 19807 presented at the 1989 Annual Technical Conference and Exhibition, San Antonio, TX, Oct. 8$11,1989$. 
10. Dindoruk, B., and Firoozabadi, A., "Immiscible Gas-Oil Flow in Fractured/Layered Porous Media," No. 1Q.93, RERI.

11. Firoozabadi, A., and Markeset, T., "Laboratory Study of Fracture Liquid Transmissibility in Fractured Porous Media," SPE 24919 presented at the 1992 SPE Annua' Technical Conference and Exhibition, Washington, DC, Oct. 4-7.

12. Eclipse Reference Manual, Version 92A, Exploration Consultants Ltd. (1992).

13. Coats, K. H., "Implicit Compositional Simulation of Single-Porosity and Dual-Porosity Reservoirs", paper SPE 18427 presented at the 1989 SPE Symposium on Reservoir Simulation, Houston, TX., Feb. 6-8, 1989. 


\begin{tabular}{|l|c|c|c|}
\cline { 2 - 4 } \multicolumn{1}{c|}{} & $1 / 2 P_{c}$ & $P_{c}$ & $2 P_{c}$ \\
\hline$h=60 \mathrm{~cm}$ & 0.399 & 0.114 & 0.0 \\
\hline$h=180 \mathrm{~cm}$ & 0.626 & 0.513 & 0.291 \\
\hline$h=360 \mathrm{~cm}$ & 0.683 & 0.626 & 0.513 \\
\hline
\end{tabular}

Table 1. $\mathrm{S}_{\mathrm{ge}}$ values for various blocks. 




Fig. 1 - Drainage rate versus $\bar{s}_{8}$ for different blocks in a stack of 10-block system. 


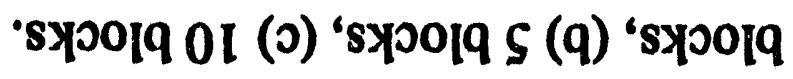

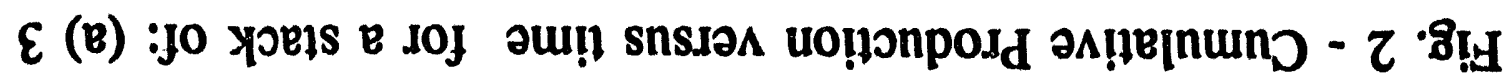
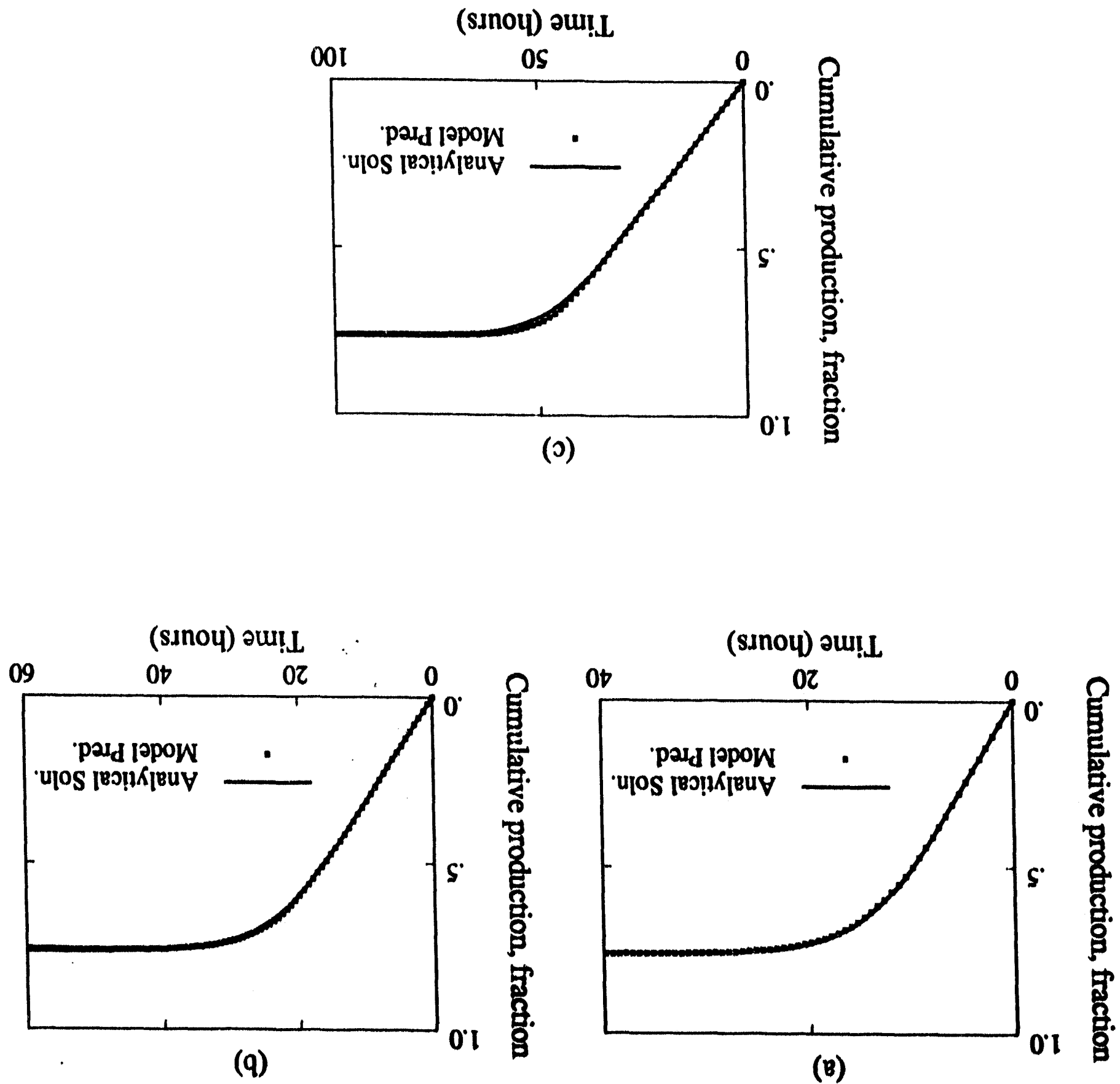


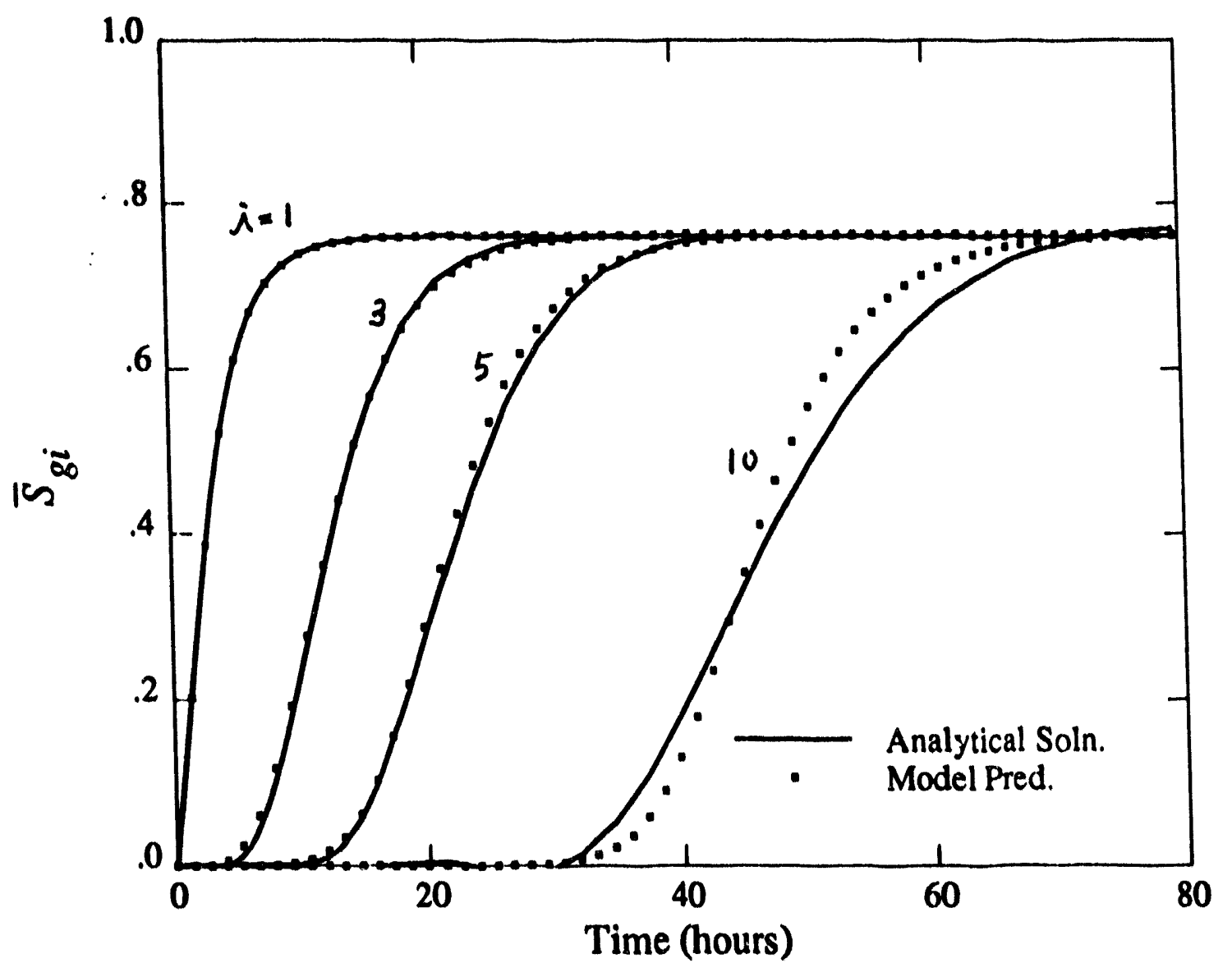

Fig. 3 - Saturation history for different blocks in a stack of 10block system. 


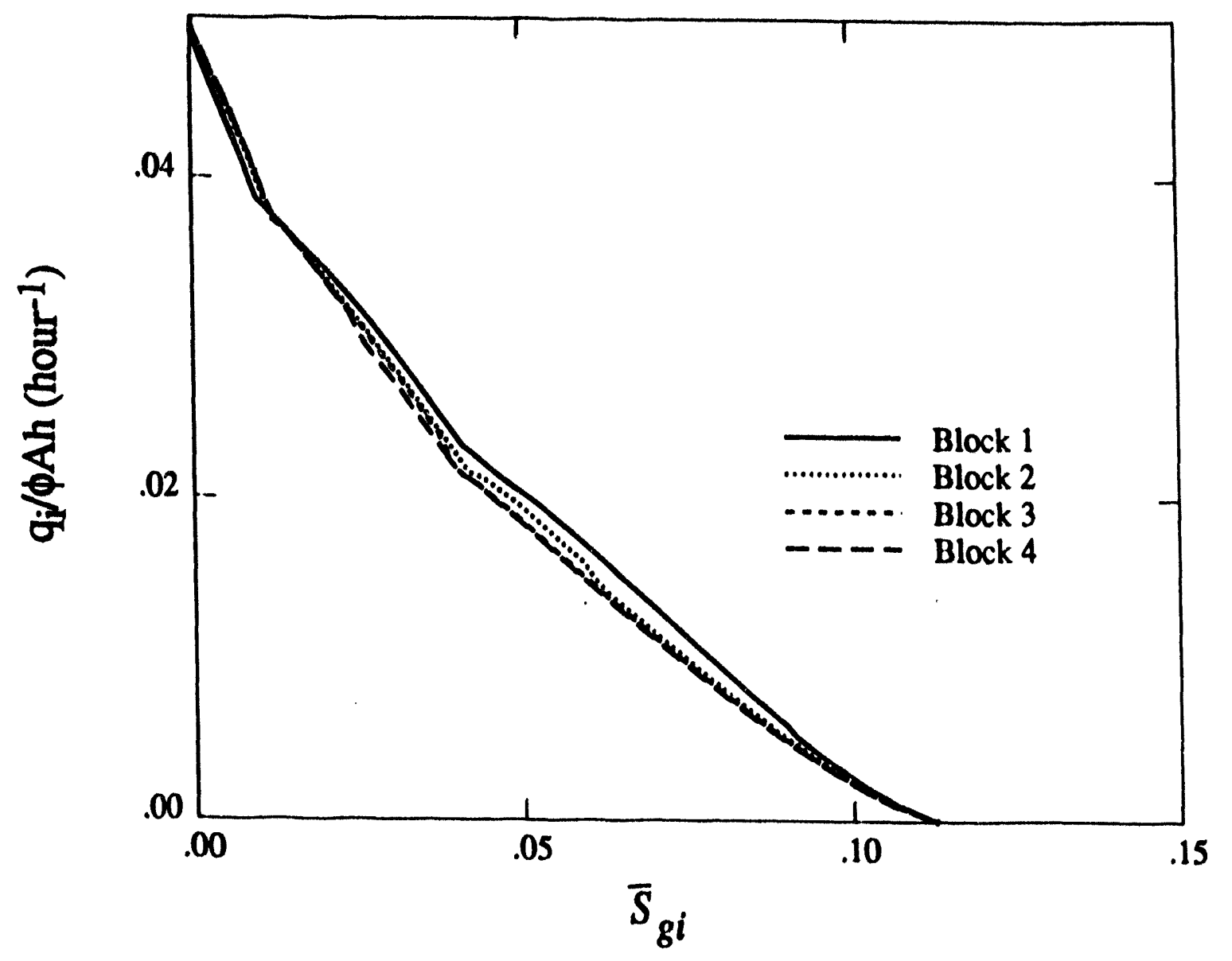

Fig. 4 - Drainage rate versus $\bar{s}_{q}$ for Case 1. 
(a)

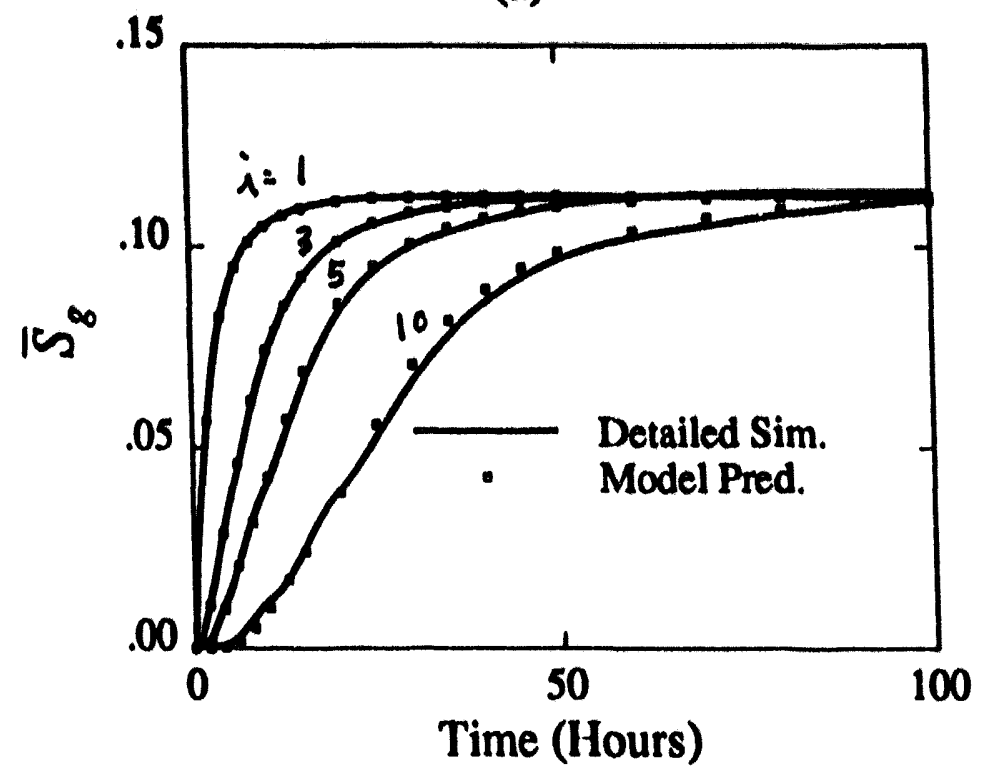

(b)

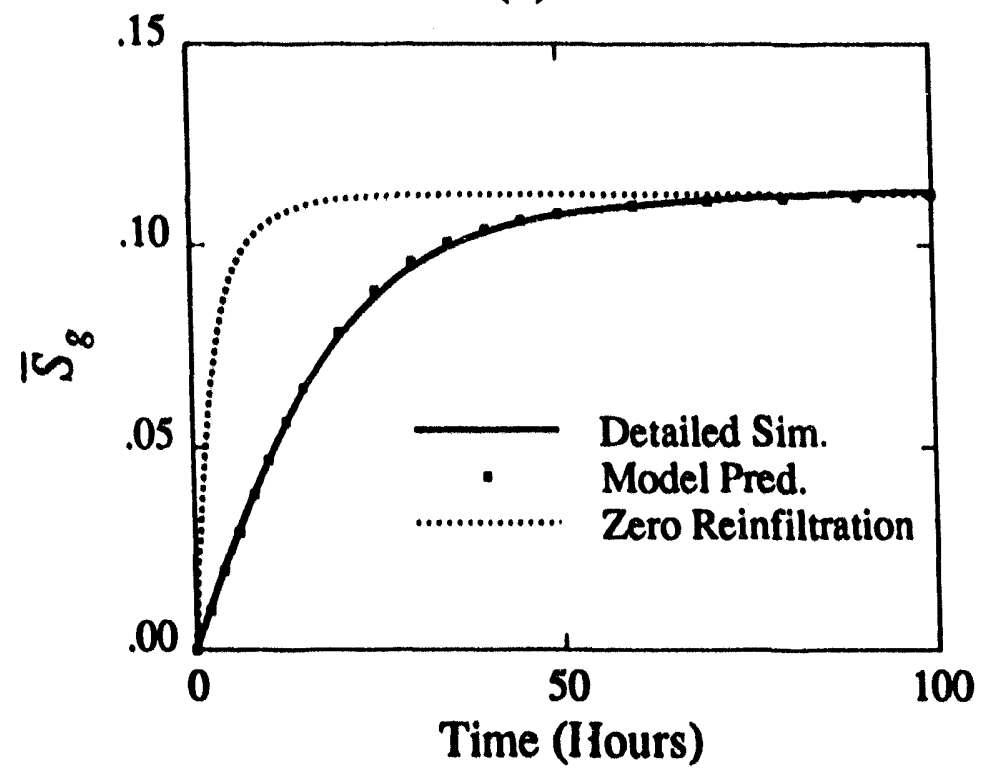

Fig. 5 - Saturation history for Case 1: (a) individual blocks, (b) entire stack. 


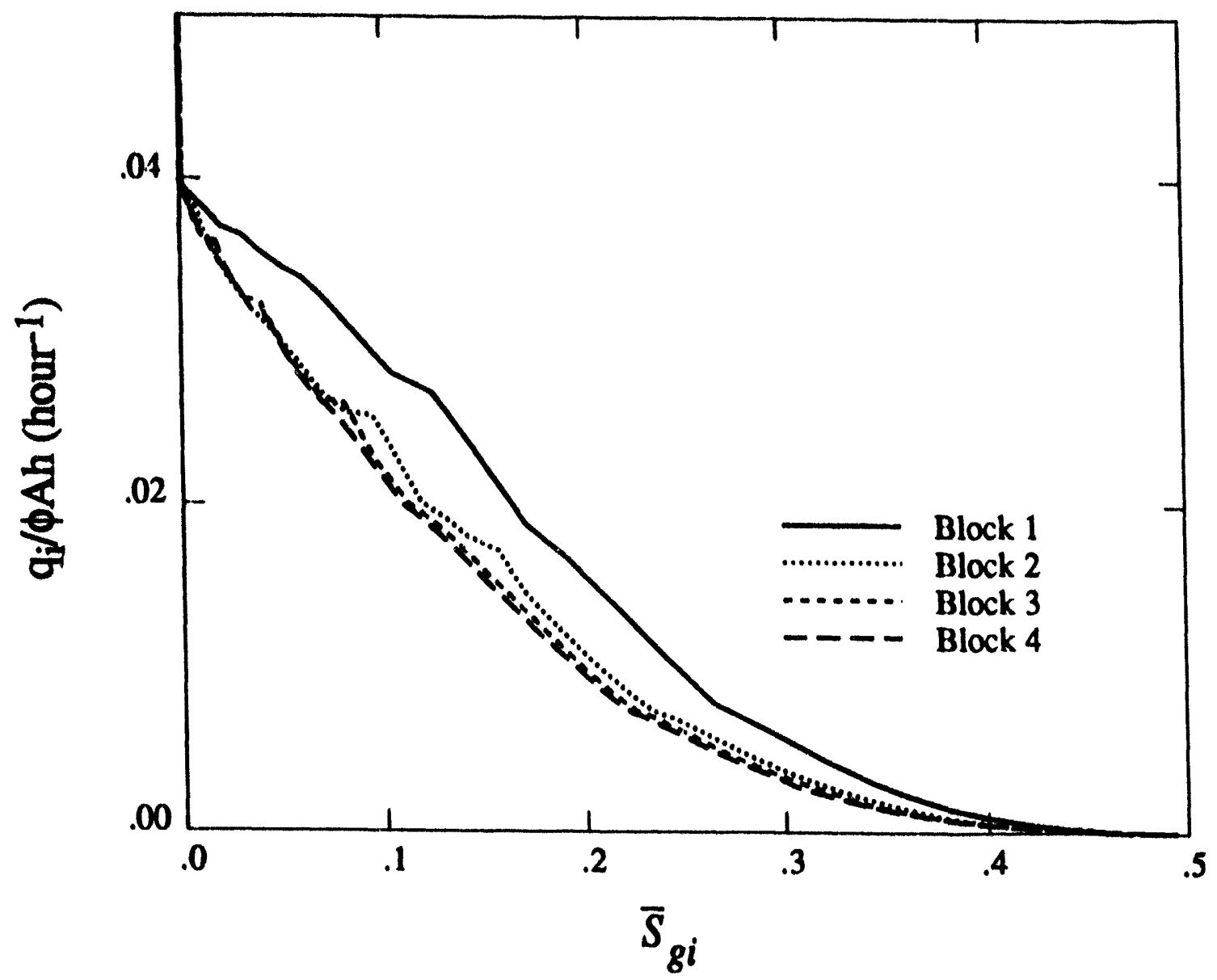

Fig. 6 - Drainage rate versus $\bar{s}_{q}$ for Case 2. 
(a)

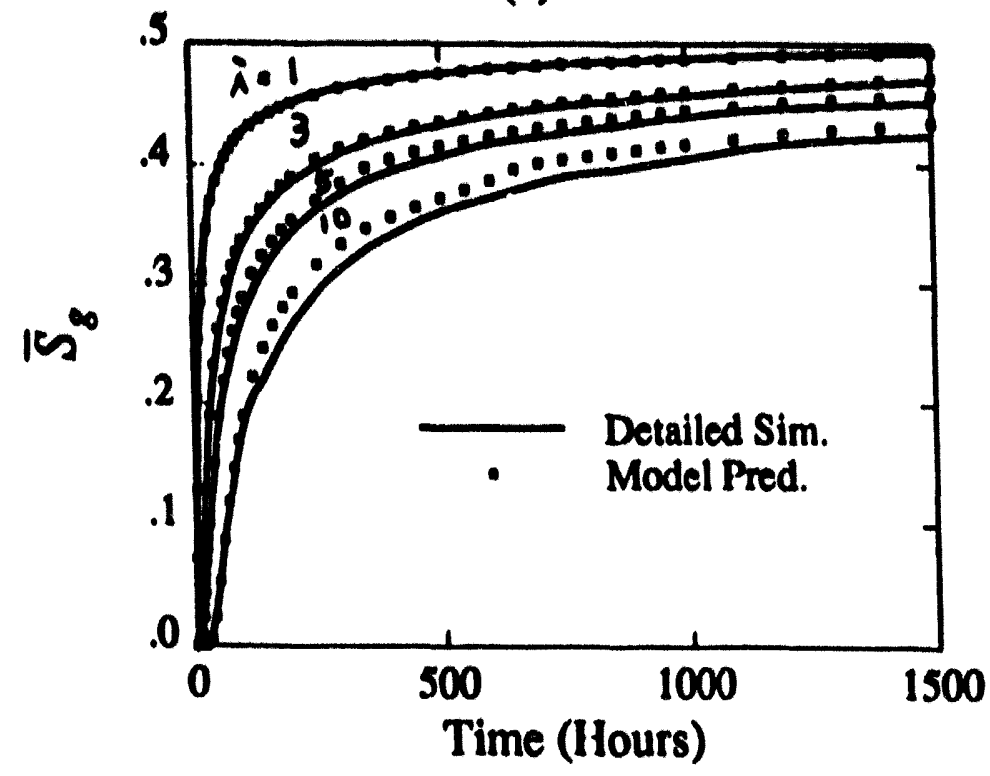

(b)

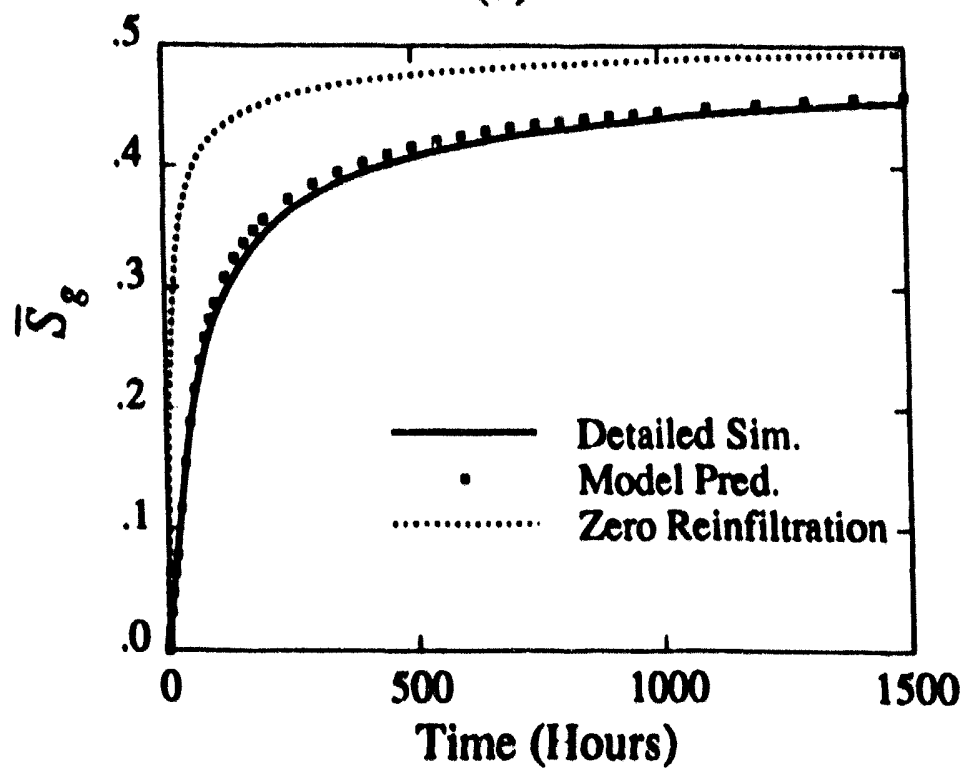

Fig. 7 - Saturation history for Case 2: (a) individual blocks, (b) entire stack. 


$\begin{array}{ll}h=180 \mathrm{~cm} & k=0.7 \text { darcy } \\ h=180 \mathrm{~cm} & k=0.1 \text { darcy } \\ h=180 \mathrm{~cm} & k=0.7 \text { darcy } \\ h=180 \mathrm{~cm} & k=0.1 \text { darcy }\end{array}$

CASE 3

$h=180 \mathrm{~cm}$
$k=0.5$ darcy
$h=0.7$ darcy
$h=180 \mathrm{~cm}$
$k=0.1$ darcy
$h=180 \mathrm{~cm}$
$k=0.4$ darcy
$h=60 \mathrm{~cm}$
$h=180 \mathrm{~cm}$
$k=0.3$ darcy darcy

CASE 4

Fig. 8 - Schematics of Cases 3 and 4. 
(a)

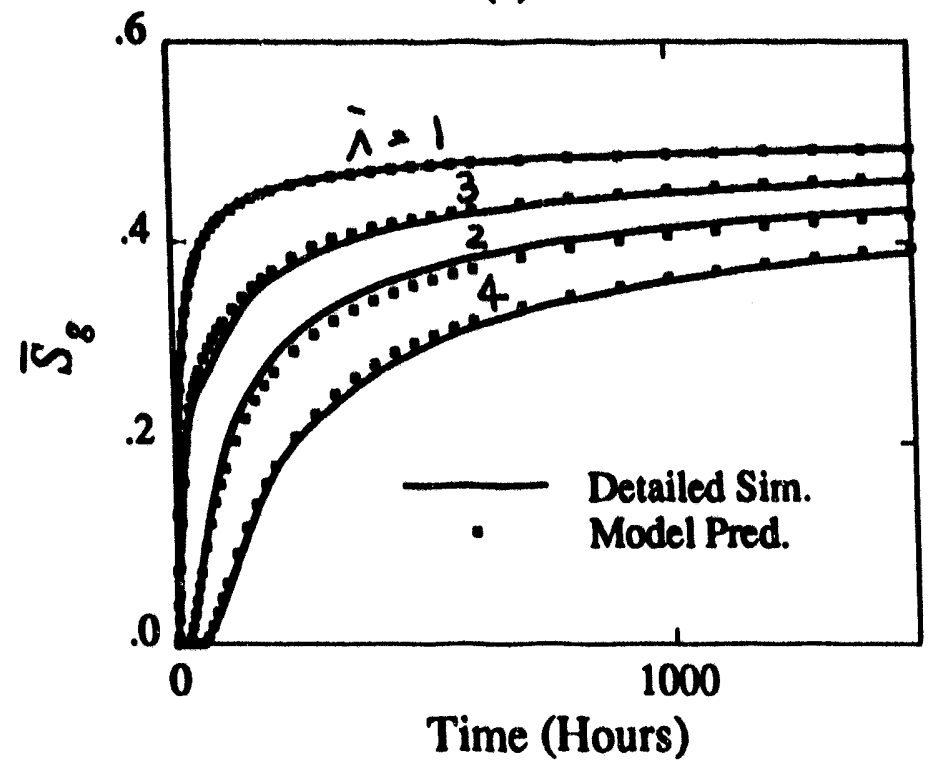

(b)



Fig. 9 - Saturation history for Case 3: (a) individual blocks, (b) entire stack. 
(a)



(b)

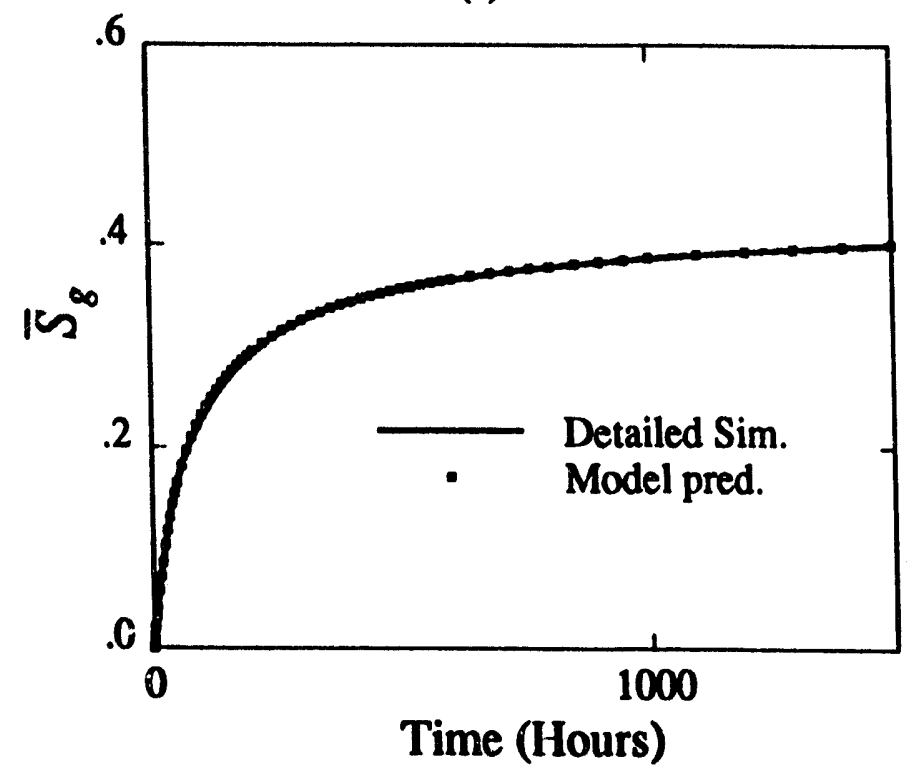

Fig. 10 - Saturation history for Case 4: (a) individual blocks, (b) entire stack. 


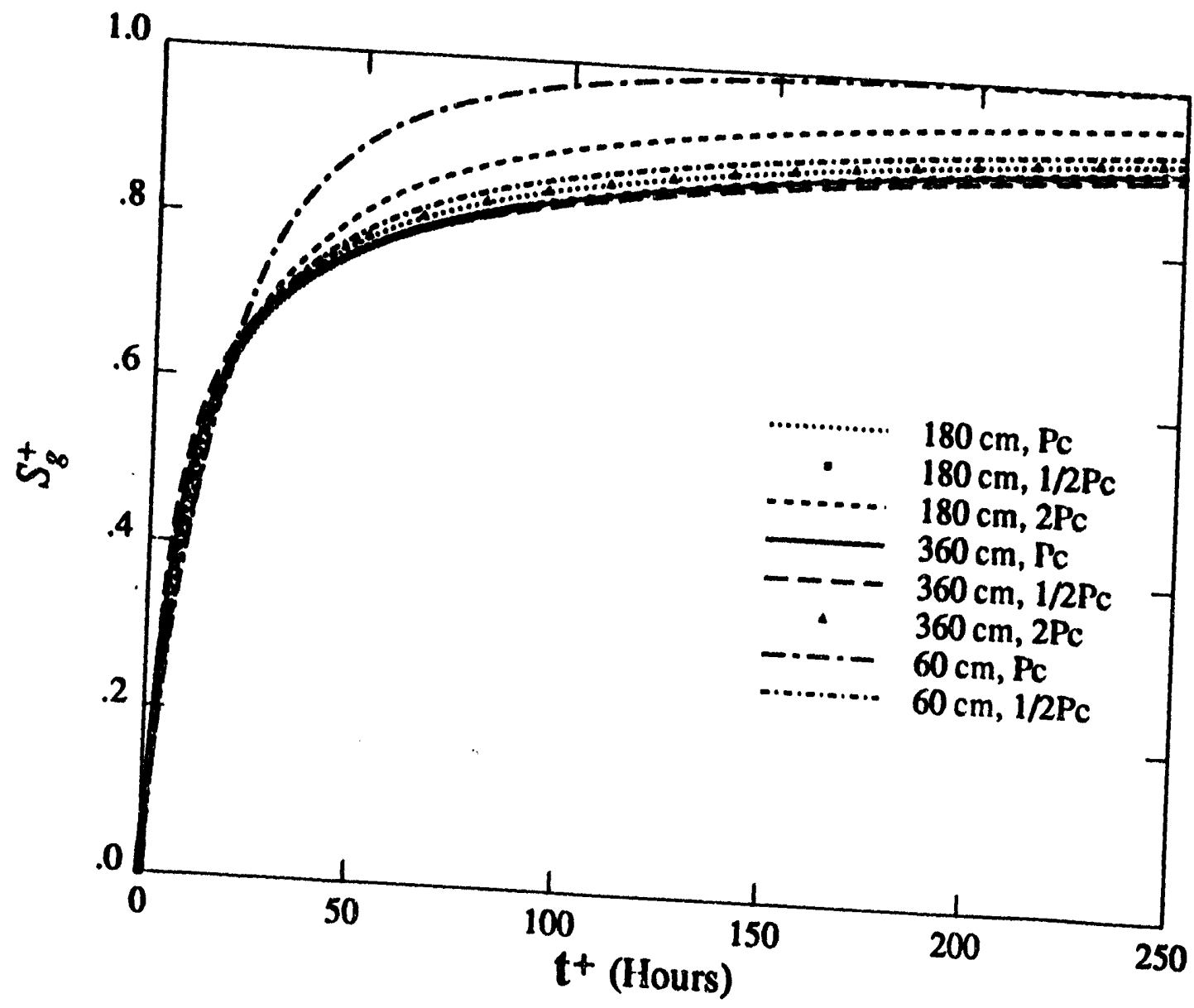

Fig. 11 - Drainage performance of a single matrix block for various matrix heights and capillary pressures. 


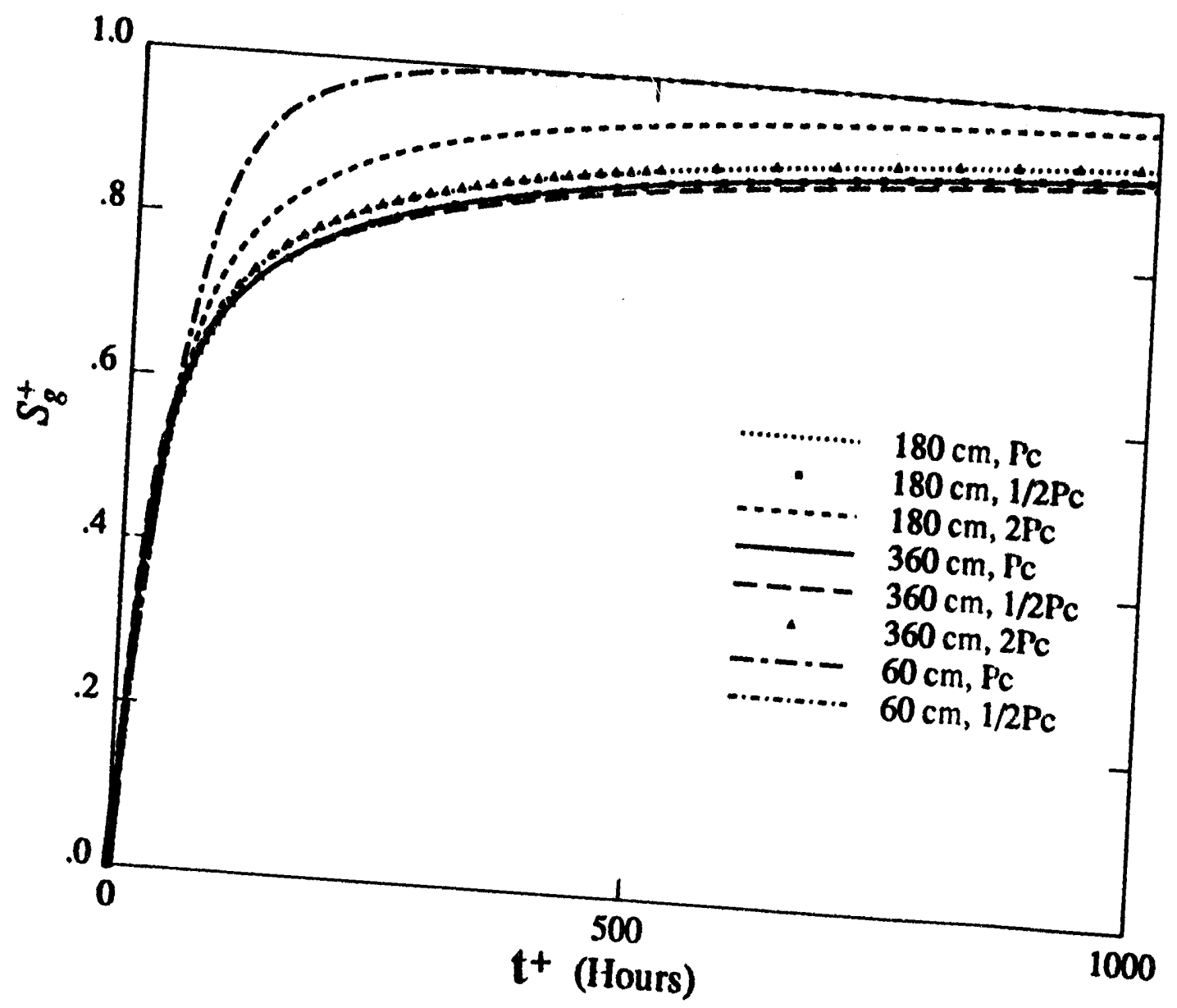

Fig. 12 - Drainage performance of a stack of four-block system for
various matrix block heights and capllay presures. 


$\begin{array}{ll}h=180 \mathrm{~cm} & k=1.5 \text { darcy } \\ h=180 \mathrm{~cm} & k=0.5 \text { darcy } \\ h=180 \mathrm{~cm} & k=1 \text { darcy } \\ h=180 \mathrm{~cm} & k=0.7 \text { darcy }\end{array}$

CAse 5

$\begin{array}{ll}h=150 \mathrm{~cm} & k=1 \text { darcy } \\ h=250 \mathrm{~cm} & k=0.7 \text { darcy } \\ h=200 \mathrm{~cm} & k=1 \text { darcy } \\ h=100 \mathrm{~cm} & k=1.5 \text { darcy } \\ h=250 \mathrm{~cm} & k=0.5 \text { darcy } \\ h=180 \mathrm{~cm} & k=0.7 \text { darcy }\end{array}$

CASE 6

Fig. 13 - Schematics of Cases 5 and 6. 


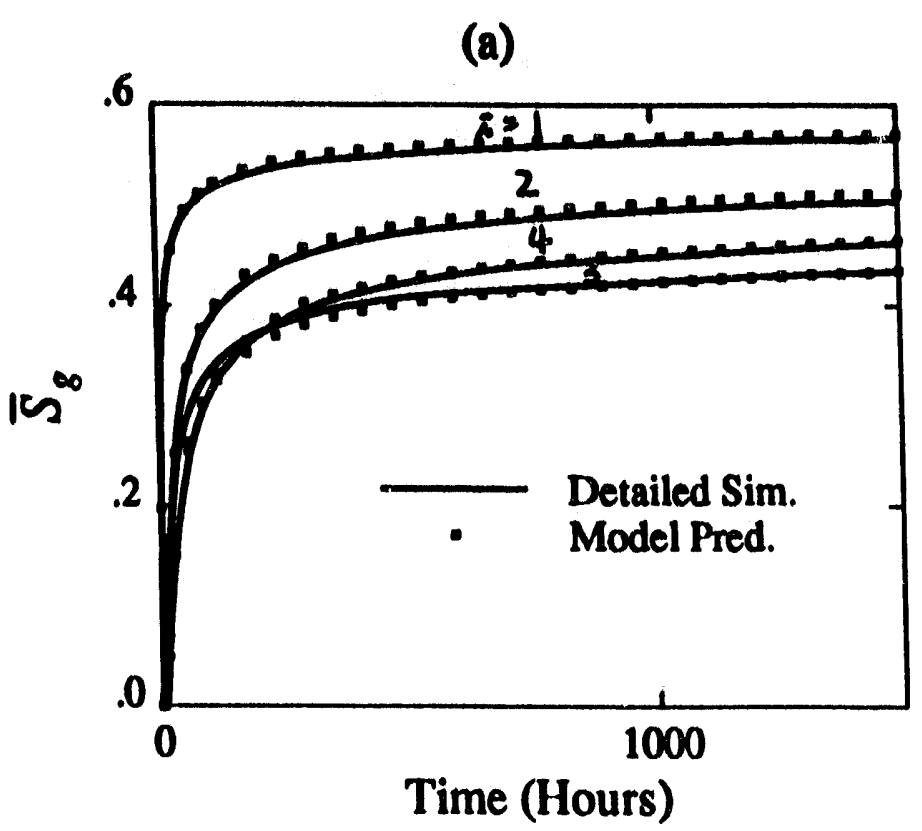

(b)

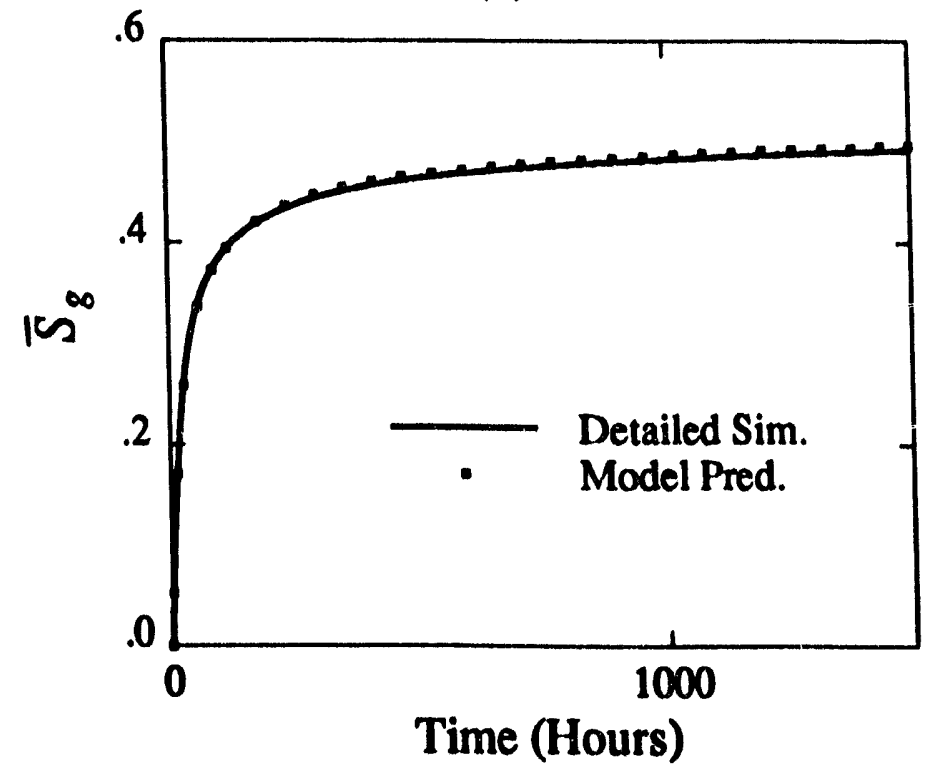

Fig. 14 - Saturation history for Case 5: (a) individual blocks, (b) entire stack. 




(b)

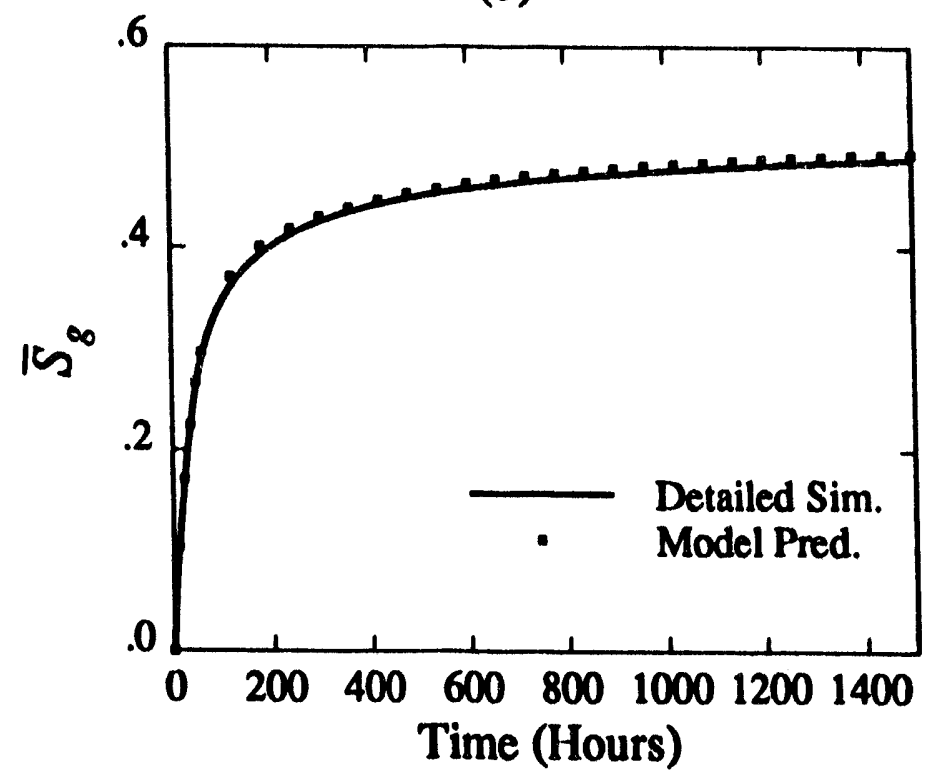

Fig. 15 - Saturation history for Case 6: (a) individual blocks, (b) entire stack. 

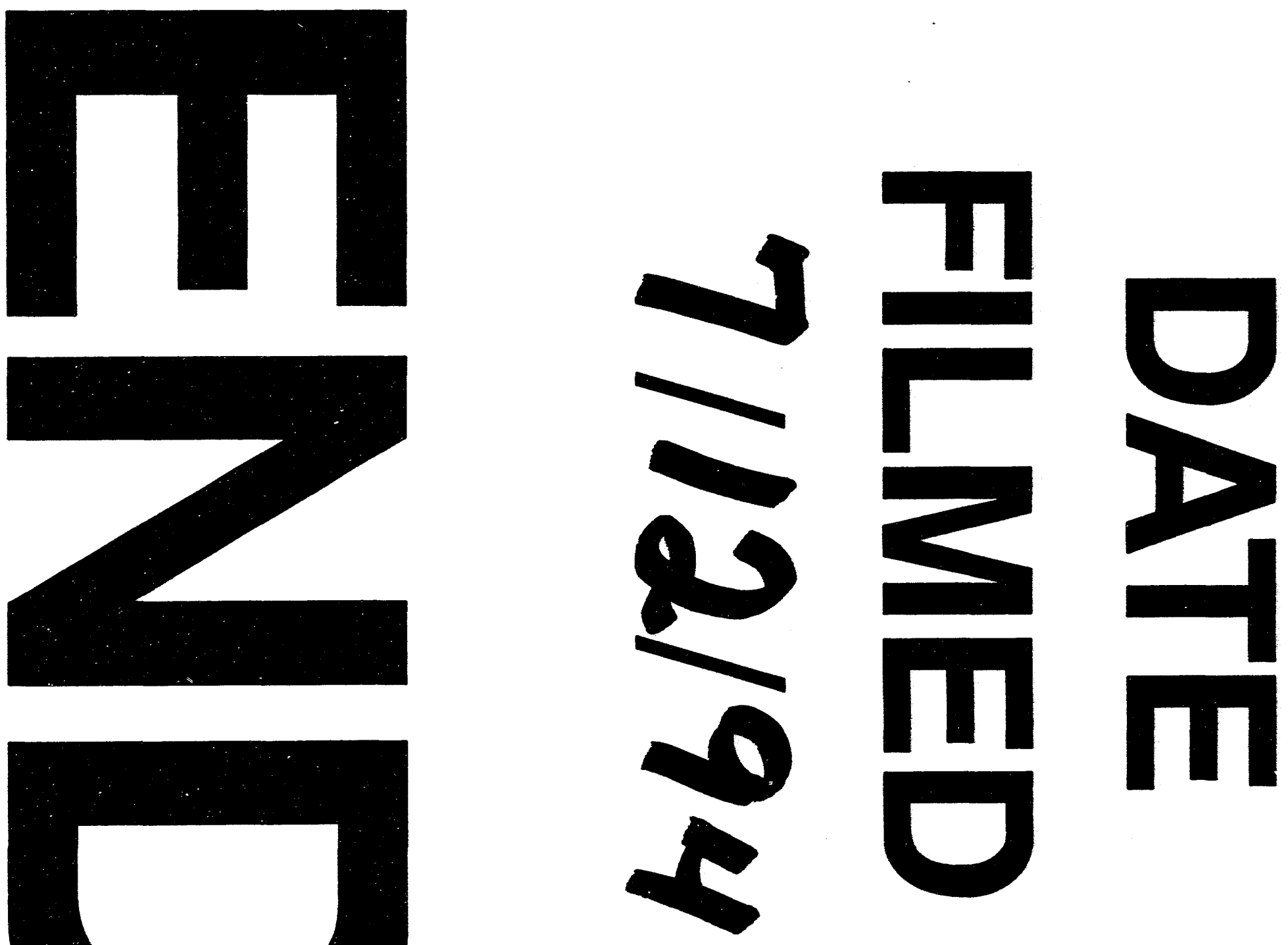

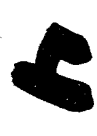




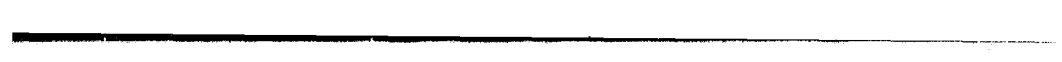

$$
-
$$

